\title{
Field Detection of Microcracks to Define the Nucleation Stage of Earthquake Occurrence
}

\author{
Y. Fujinawa, ${ }^{1}$ Y. Noda, ${ }^{2}$ K. Takahashi, ${ }^{3}$ M. Kobayashi, ${ }^{4}$ K. Takamatsu, ${ }^{4}$ and J. Natsumeda ${ }^{4}$ \\ ${ }^{1}$ Risk Control Association, Kanda Hirakawa Chiyoda-ku, Tokyo 101-0027, Japan \\ ${ }^{2}$ Tierra Tecnica Ltd., Musashimurayama, Tokyo, Japan \\ ${ }^{3}$ Communication Research Laboratories, Koganei, Tokyo, Japan \\ ${ }^{4}$ OKI Engineering Co., Ltd., Nerima-ku, Tokyo, Japan
}

Correspondence should be addressed to Y. Fujinawa; hjfujinawa@cl.cilas.net

Received 4 July 2013; Revised 21 September 2013; Accepted 28 October 2013

Academic Editor: John P. Makris

Copyright (C) 2013 Y. Fujinawa et al. This is an open access article distributed under the Creative Commons Attribution License, which permits unrestricted use, distribution, and reproduction in any medium, provided the original work is properly cited.

\begin{abstract}
Main shocks of natural earthquakes are known to be accompanied by preshocks which evolve following the modified Ohmori's law in average over many samples. Individual preshock activity, however, is far less systematic for predictive purposes. On the other hand, the microcracks in laboratory rock experiments are always preceded to final rupture. And, previous investigations of field acoustic emissions showed that the activity increases prominently before and after the main shock. But there is no detection of any phenomena to identify the nucleation stage. Here we show that a special underground electric field measurement could detect microcracks. Pulse-like variations were classified into three groups (A, B, C) by frequency. The B-type is suggested to define the nucleation period: activity increases sharply following the modified Omori's law before the main shock and there is no activity afterward. The B-type is subgrouped into three types possibly corresponding to crack-rupture modes. The variations are supposed to be induced by crack occurrence through electrokinetic effects in the elastic-porous medium. The detection distance is suggested to be several orders larger than that of the acoustic emission due to the effective smallness of dissipation rate, and the waveform can be used to infer the rupture mode.
\end{abstract}

\section{Introduction}

The identification of anomalous phenomena in each stage of seismic cycle is a prerequisite for understanding physical processes to be applied to earthquake forecasting (e.g., Mogi [1], Rikitake [2], and Scholz [3]). For the short-term prediction, numerous observations by seismic, geodetic, hydrologic, and electromagnetic approaches have been tried to investigate various phenomena to find precursory phenomena and to build physical and statistical models $[1,3]$.

Among all, the preshock has been considered to be the most direct and plausible phenomenon for identifying the earthquake nucleation stage. Previous investigations of preshock activity of natural earthquakes or microcracks activity in laboratory experiments (e.g., [1, 3], Jones and Molnar [4], Ohnaka [5], and Maeda [6]) have provided essential evidence as accelerating activity. Those evidences have been utilized to build the physical and statistical models of nucleation process
$[1,5]$. These models have been further developed: for instance, superimposed undulation of foreshock activity was utilized to infer dynamical critical phenomena to estimate more exact final rupture time (e.g., Sornette and Sammis [7], Kapiris et al. [8], Eftaxias et al. [9], and many papers referred in the report).

As for natural earthquakes, however, the evidence is generally limited to average images. There is large extent of variability in particular cases of earthquake with the result of no plausible clue to be applied for prediction of individual earthquake (e.g., [3]). The most crucial problem is too small number of preshocks to fit the characteristic formula of the evolution to infer the nucleation stage. For instance only four and three preshocks were observed in case of the Hyogoken Earthquake (M7.2, January 17, 1995) and the Tohoku Earthquake (M9.0, March 11, 2011), respectively. The situation has not been improved even by the most extensive microseismic network (Hi-net) of Japan. 


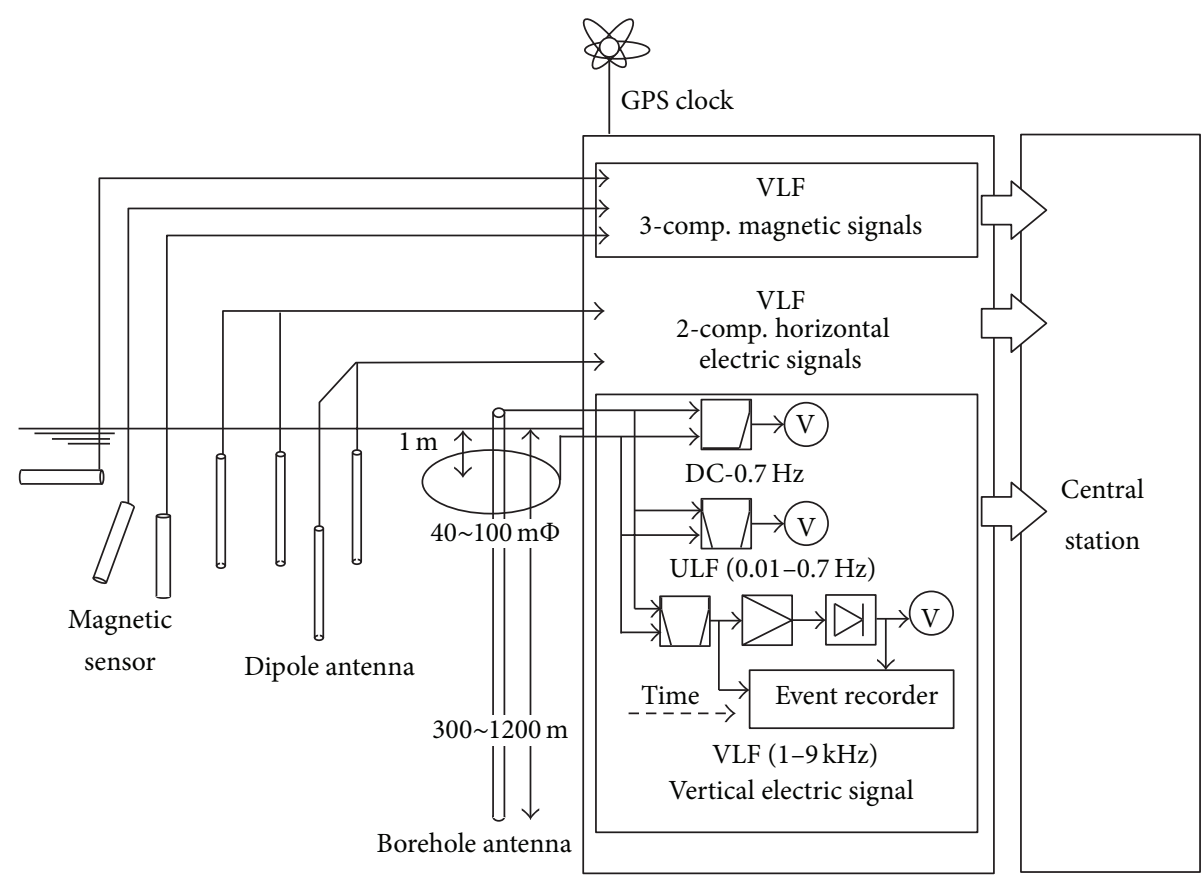

FIGURE 1: Schematic diagram of multiple component electromagnetic field observations $[25,28]$ of the full option. The electric field is measured by a pair of horizontal dipoles of $8 \mathrm{~m}$ in length with a span of $20 \sim 50 \mathrm{~m}$ and using a vertical monopole of $600-1,200 \mathrm{~m}$ surrounded by wire with a radius about $10-20 \mathrm{~m}$ buried at a depth of about $1 \mathrm{~m}$. The magnetic field is measured by three induction-type magnetometers (BF6, EMI) installed perpendicularly to each other. Triggered data in three electrical and magnetic fields are transmitted to a central station once a night. The present observation at Hasaki was conducted by the simplest model using only borehole sensor with continuous data acquisition.

On the other hand, the rock fracture experiment can always observe the characteristic rapid increase of acoustic emission activity in the nucleation period [1, 3, 5, 10-14]. Especially the accelerated increase of microcracks is shown to follow the modified Ohmori Law. Detailed investigation on activity in terms of spatiotemporal distribution and focal mechanism of microcracks revealed physical process of rock fracture. The investigation extends to the seismoelectromagnetic phenomena (e.g., Hayakawa and Fujinawa [15], Hayakawa [16], and Eftaxias and Potirakis [17]).

The acoustic emission technique has been widely used in the geotechnical engineering field to examine geological materials since the late 1930s (e.g., Drnevich and Gray [18]). The technique has been used for monitoring the mine and stones by using dense seismic network with spacing of several tens of meters. Concerning natural earthquakes, however, there are only several pioneering studies to investigate field acoustic emission activities (e.g., Morgunov et al. [19], Hattori [20], and Molchanov et al. [21]). Those researches showed that the acoustic emission intensity is high about half-day both before and after the earthquake occurrence. The index of the activities are limited to the strength and could not distinguish the difference between the activity before the main shock and that after the shock without providing any useful clue to define the nucleation stage.

Electromagnetic approaches have been providing many interesting clues to shed light on preparatory process of earthquakes (e.g., Park et al. [22]). As for the nucleation process of natural earthquake, Eftaxias has been investigating in detail by referring laboratory and earthquake generation model by assuming that the VLF emissions are induced by the microcracks $[9,17]$.

In the present paper we present an electromagnetic field observation of microcracks by using high quality instruments providing new clues to detect particular features to identify the nucleation stage.

\section{Methods}

2.1. Sensor. We used electric sensors to observe microcracks instead of ordinary acoustic emission transducer. The sensor in the field is a special antenna made of a vertical casing pipe that is installed into a borehole of 200 to $1,800 \mathrm{~m}$ deep. The boreholes are not for electric field measurement but for intrinsic purposes as measurements of seismic motion, ground water level, and chemical contents; ground deformation or pumping of natural gas or waters for drinking; and hot spring belonging to several organizations and private persons (Fujinawa et al. [23-25]). The antenna is one of monopole type immersed underground (Figure 1) of conductive crust similar to the towing tail cable antenna for submarines' underwater communication.

The electrical circuit is composed of the preamplifier, filtering, and data logging. Additionally a simple counter surge circuit is inserted between sensors and preamplifiers to withstand electric surge induced by lighting discharge. The recording frequencies are DC band $(0-0.7 \mathrm{~Hz})$, ULF (0.001-0.7 Hz), and ELF/VLF (1 kHz-9 kHz). The data of VLF 


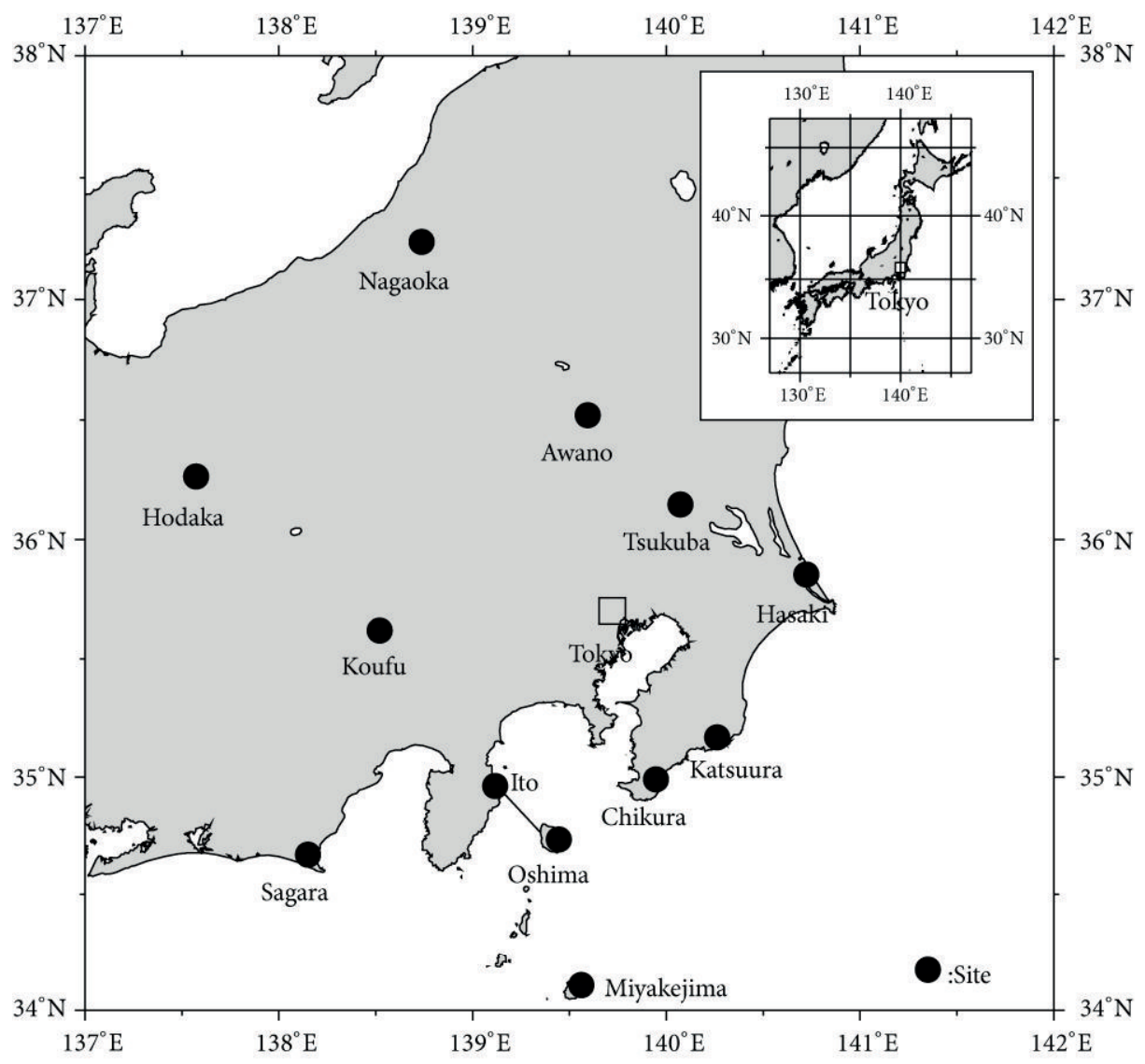

FIGURE 2: Locations of the electromagnetic field observation sites ( $\bullet$ in central Japan utilizing borehole antenna $150-1200 \mathrm{~m}$ long as the principal sensor. Those sites have been constructed during 1989 1996. Every site measures the vertical component of the electric field. Additionally mutually perpendicular short dipoles of 20 60 m long were used for measurement of horizontal electric component at five sites (Hasaki, Chikura, Koufu, Nagaoka and Sagara) by 2002. And the induction type magnetometers were used at two sites (Nagaoka, and Sagara) by $2002[25,28]$.

band is logged by an event trigger system focused to locate the VLF pulse-like signal for early stage of investigation. Later envelope of electric strength is recorded to monitor the activity of the field. Lower frequency component is recorded continuously with the sampling interval of 2 seconds. The present observation used continuous recording.

2.2. Prior Observation. Prior observation has confirmed that the system has high robustness against both meteorological and urban noise enabling us to get large signals related to the crustal activities (Fujinawa et al. [23-26], Takahashi et al. [27]). Exceptions are the large noises induced by nearby lighting discharges and smaller "noises" by severe geomagnetic disturbances compared with the normal state. After confirming the performance of the borehole antenna the observation was conducted only by borehole antenna.

The observation network has been built and operated since 1989, and the sites situate at several kinds of geological conditions nearly uniformly in central Japan (Figure 2). Several kinds of anomalies were picked up and investigated from the points of view of finding and evaluating candidates of precursor in relation with earthquakes, volcanic eruption, and ground slides. The ULF band anomalies have been most extensively investigated because they were detected at almost cases of nearby volcanic eruption at Izu-Oshima and MiyakeJima and seismic swarms as Hodaka in a geothermal region near volcanos (Fujinawa et al. [25]).

The ULF band characteristic waveform was first identified by the temporally rapid recording at the time of volcanic eruption activities in 1990 at Izu-Oshima (Figure 3, Fujinawa et al. [23]). The signals have never been detected in a normal state, but observed in almost all volcanic eruption activities and seismic swarms occurring near the observation sites: the earthquake swarm around Mt. Hodaka in 1998 (Takahashi et al. [28]) and Mt. Nikko-Shirane in 1999, and volcanic eruption at the Miyake Island in 2000. The phenomena have been suggested to be induced by an electrokinetic effect (e.g., [25, 26]; Nourbehect [29], Fitterman [30], and Ishido and Muzutani [31]. The ULF variation is called a "geyser-like ULF signals (GUV)" because of similarity of the temporal change of electric strength with water height change of the geyser. We imagined that the whole of the pulse-like 


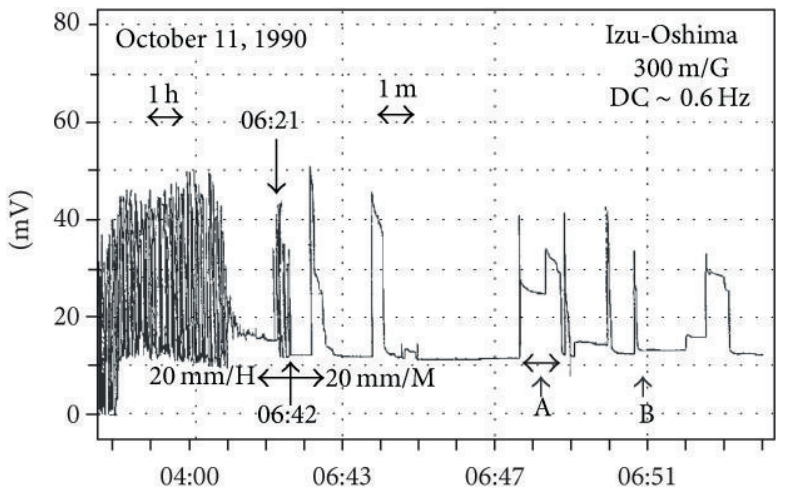

(a)

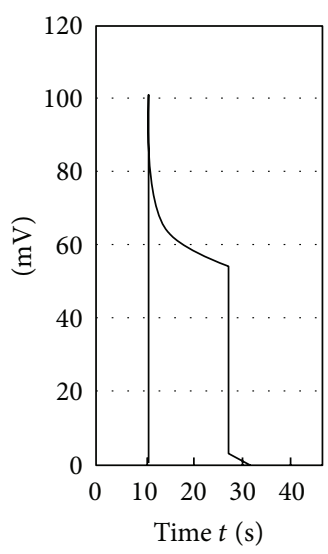

(b)

Figure 3: (a) Records of electric field anomalies on 11 October, 1990 related to the small volcanic activities in the Izu-Oshima Island by the borehole antenna $[25,28]$. Slow speed recording shows numerous pulse-like signals (left part of (a) before 6:42 JST). Rapid recording by 60 times (right part of (a) after 6:42 JST) shows the particular waveform similar to the geyser height evolution. (b) A model of confined pressure change is proposed to explain the electric field changes based on the electrokinetic effect.

variations detected by the slow speed recording are of this type. We could not analyze higher-frequency phenomena in detail because of the system's slow recording speed.

2.3. New Detector and Observation. The present observation was conducted using detectors having larger dynamic range. The experiment was originally to investigating the coseismic signals with propagating velocity much larger than the seismic wave (Fujinawa et al. [32] and references in the literature). We installed a new detection system on 3, March 2011 at Hasaki (Figure 2, now Kamisu), which is about $300 \mathrm{~km}$ south of the epicenter of the Tohoku Earthquake (Figure 4, modified from Suzuki et al. [33]). The borehole belongs to the National Research Institute for Earth Science and Disaster Prevention (NIED). The frequency bands are of DC $(0-1.45 \mathrm{~Hz})$ and $\mathrm{AC}(1.45 \mathrm{~Hz}-9 \mathrm{kHz})$. AC recording band is amplified by gain of 100 . And the sampling rate is $4.5 \mathrm{kHz}$ before March 11, $18 \mathrm{kHz}$ from 24, March, 2011.

2.4. Data Analysis. To construct diurnal monitoring of DC and $\mathrm{AC}$ components we averaged in the interval of $1 \mathrm{sec}$ and/or resampled by $150 \mathrm{~Hz}$ from the original data sampled $4.5 \mathrm{kHz}$ (by 11th March or $18 \mathrm{kHz}$ after 24th March). Figure 5(a) illustrates the result of the averaging every second for one day data on March 25. Figure 5(b) is another record for diurnal monitoring using data through both resampling by $150 \mathrm{~Hz}$ and averaging of $1 \mathrm{sec}$. Difference is in apparent background noise levels of $0.003 \mathrm{mV}$ and $0.040 \mathrm{mV}$ for the procedure without and with $150 \mathrm{~Hz}$ sampling, respectively. The larger noise level for $150 \mathrm{~Hz}$ resampling suggests the procedure without $150 \mathrm{~Hz}$ resampling is more suitable to monitor the activity of the events. It is noted that the averaging procedure reduce the pulse strength with the result of difference of pulse strength in the monitoring and individual events. After finding there are pulse-like events, we picked up whole events of strength larger than predetermined threshold of $2 \mathrm{mv}$ from original raw data. There are no other procedures to depict meaningful signals except those induced by lightning surge in this method of measurement having high robustness.

\section{Results}

Figure 6(a) is the daily DC monitoring record on March 31, 2011 corresponding to the calm state. Except the background noises there were only diurnal variations due to the effect of earth and ocean tide (e.g., Lai et al. [34]). On the other hand the record on March 25 (Figure 6(b)) includes large pulse-like variations. Figure 6(c) is AC daily record on March 4 showing normal state for background noises of about $0.03 \mathrm{mV}$ seen as a belt except short time period of activity between 17:00 and 19:00 ("Activity" in c)). Contrary to this normal record, March 9 (Figure 6(d)) had numerous pulses.

Whole pulse-like variations with strength greater than $2 \mathrm{mV}$ about 40 times the background noise level of $0.025 \mathrm{mV}$ were picked up from the raw data. There were a total of 225 events. The successive large pulses corresponding to nearby lightning have not been detected. Most of the events are isolated in the sampled interval of $100 \mathrm{~ms}$ except cases superimposed small events as described in the discussion section. The largest event is of the coseismic variation corresponding to the main shock reported previously [32]. The event is taken up later in the discussion section. Waveforms of the whole events were enlarged for the investigation of their characteristics and origin. Those events are found to be classified into three groups depending on their signal duration. The typical waveforms in each group are shown in Figure 7. Whole pulse-like signals belong to one of the three types indicating that there are no extraneous noises.

The type of an event (Figure 7(a)) was simply the socalled ULF geyser-like variation of the sort that had been recognized earlier (GUV) [23, 25, 26] by us as is shown in Figure 3. The ULF variations have been investigated also by many authors from the point of view for prediction of 


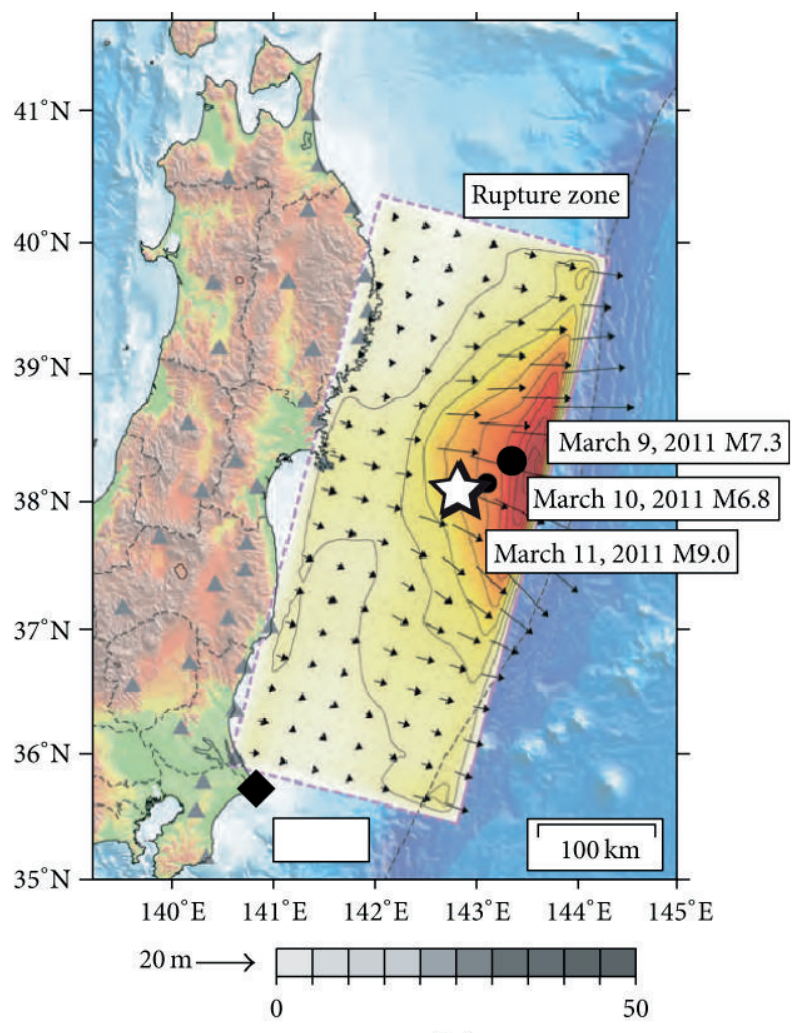

$(\mathrm{m})$

FIGURE 4: Geographical relationship between the observation site Hasaki $(\diamond)$ and the rupture zone $500 \mathrm{~km} \times 200 \mathrm{~km}$ (dashed line). Calculated displacement distribution $(\nearrow)$ of the Tohoku Earthquake ( $\star$, magnitude 9.0). Also shown are the two largest preshocks, which

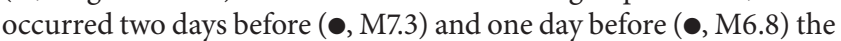
earthquake (revised from Suzuki et al. [33]).

earthquake and volcanic eruptions by using electromagnetic measurement on the surface (e.g., [8, 9, 21-23], Nagao et al. [35], Revil and Saracco [36], and Han [37]). But there are still no consensus on the characteristics of waveform and the generation mechanism, though there are large extent of similarity in the waveforms and pulse width and uniformity of amplitudes.

Types B and C events were firstly identified in this observation of increased dynamic range in our method. They have a much smaller duration time from $10 \mathrm{~ms}$ to several tens of ms for type B and 0.3-0.5 ms for type C compared with that of A-type of several minutes.

Type B pulses are subdivided into three types depending on their waveform (Figures $7(b)-7(d)$ ). Main phase of the type B-1 (Figure 7(b)) is similar to type A in its abrupt rise and maintaining polarity similar to the relaxation waveform, but is different in decaying stepwise. It is noted that almost all events of B-1 contain higher frequency components.

Similar electric variation without stepped decays had been previously reported in association with acoustic emission in rock deformation experiments [10-14]. The electric field variation associated with the acoustic emission was detected in the time period of stable sliding in the nucleation period. For the dry granite the variation has high similarity with B-1 type in the points that rapid growth followed by exponential decay with dominant positive polarity. The differences to the present case are in different time constants of $50 \mu$ second and in compound rate of dominant phase of lower frequency with higher frequency components. In case of stick-slip movement, they found the variation similar to the wave packet type of B-2 without P phase. Moore and Glaser [38] reported similar self-potential spikes with less sharp rise of electric field change in hydraulic fracturing experiment.

The simple relaxation type electric variation was also deduced in the analytical estimation by Fenoglio et al. [39] concerning magnetic anomalies associated with the Loma Prieta Earthquake1990 (Fraser-Smith et al. [40]). In that model, confined water is assumed to eject as the Poiseulle flow during crack opening inducing electric field changes through the electrokinetic effect.

Type B-2 (Figure 7(c)) is a wave packet similar to the seismic wave and acoustic emission waveform. But the dominant frequency is $1-2 \mathrm{kHz}$ several orders smaller. In the rock fracture experiment using wet granite Yoshida and Ogawa [13] detected high frequency variations of dominant frequency of $0.3 \mathrm{MHz}$ having similar waveforms as B-2.

Type B-3 (Figure 7(d)) is a superposition of types B-1 and B-2 with various rates of compounding. The waveform compounded by relaxation type variation can be seen also in the results of Yoshida and Ogawa [13]. The starting time difference of the two components is short enough to suggest that they are due to the same dynamic motion. The source mechanism of the microcracks was determined using the moment tensor method by Sellers et al. [41] and Timms et al. [42]. They revealed that many cases have an isotropic component corresponding to tensile opening or compressive closure. The mixed waveform B-2 is thought to be caused by a crack of this composite type of mechanism. The catalog of all B-type variations is shown in the appendix.

Type C (Figure 7(e)) is a wave packet with a carrier frequency of about $5 \mathrm{kHz}$, about ten times larger than that of type B-2 and the shortest duration of some $0.5 \mathrm{~ms}$. Amplitude reaches some $30 \mathrm{mV}$ several times larger than that of $\mathrm{A}$ and $\mathrm{B}$ type. This type does not seem to be subdivided as B type under the limit of present sampling interval.

In the crack theory [3], it is known that the displacement field of a crack has three modes: tensile mode (I) and shear modes of two types: in-plane shear mode II and antiplane shear mode III. The space and time distribution and focal mechanism of microcracks were investigated in rock experiments [38-42], Lei et al. [43]. And it was found that tensile-type cracks occur rather uniformly in space and time, whereas shear-type cracks tend to concentrate in the area of unstable movement. Based on previous and present findings, we can suggest that type A and type B-1 correspond to tensile cracks, types B-2 and C to shear modes, and type B-3 to the compounded mode.

Figure 8 shows the time evolution of the number of pulses per hour of types A (green), B (red), and C (blue). The observation of this session started 13:00, March 3, 2011 till 13:00, March 30. There are several time periods of recording interruption (horizontal grey bold line) owing to malfunction 


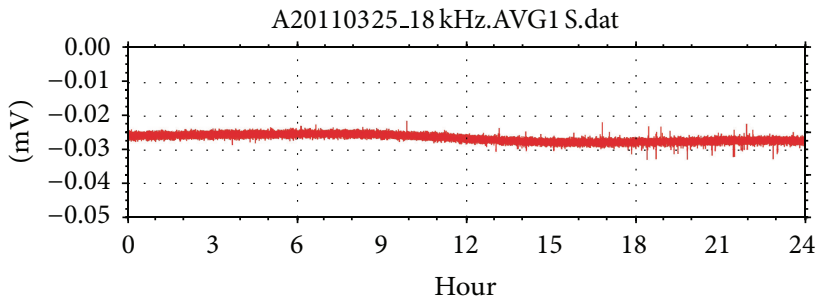

(a) Simple average $(1 \mathrm{sec})$

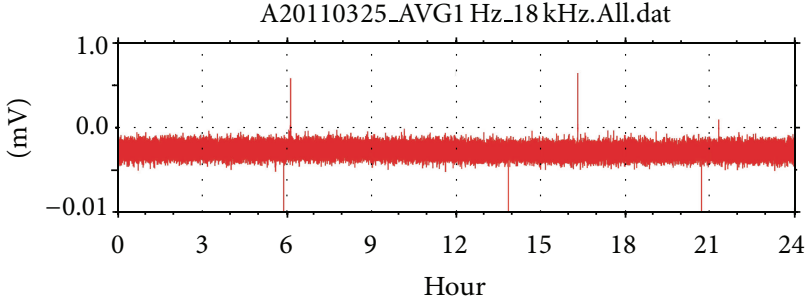

(b) $150 \mathrm{~Hz}$ sampling and average $(1 \mathrm{sec})$

FIgURE 5: Comparison of two kinds of monitoring data. (a) Raw data on 25th March 2011 sampled by $18 \mathrm{kHz}$ and averaged for 1 second. Small drift of about $0.003 \mathrm{mV}$ is due to the limit of circuit performance. (b) The same raw data through resampling by $150 \mathrm{~Hz}$ and averaged for 1 second.

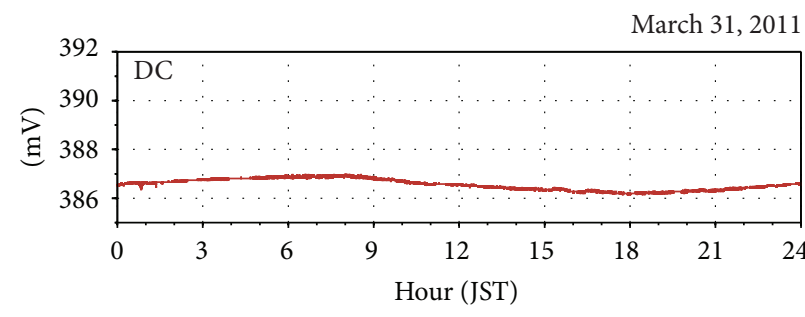

(a)

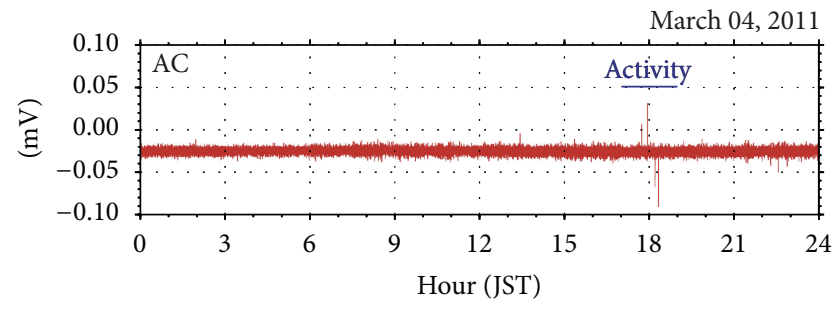

(c)

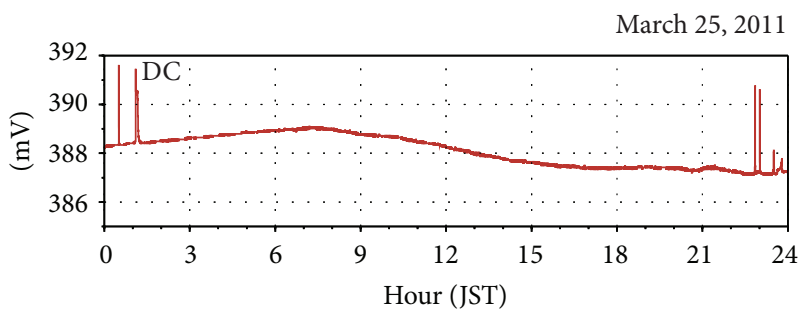

(b)

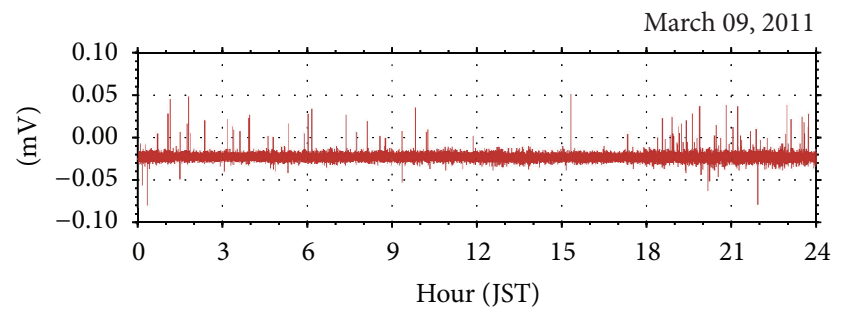

(d)

FIGURE 6: Monitoring records of normal state and active state. (a) DC channel record on March 31, 2011 corresponding to the normal state without any short period fluctuation of large strength except for a diurnal variation due to the earth and ocean tide. There were no conspicuous environmental noises to make it difficult to detect anomalous signals. (b) DC channel record on March 25 with pulse-like fluctuations around 1:00 and 23:00. The signals are very similar to those found in the analog record at several cases of crustal activities [25, 26]. The strength of the signal is about twice as large as the earth tide. (c) The AC channel record on March 4 corresponding to the normal state except during the time period 17:00-19:00. During the calm state there were no large variations except for the atmospherics and environmental noises comprising a horizontal belt-like part. (d) AC channel records on March 9 corresponding to the most active day. The amplitude of the pulse has a distribution, and the positive polarity dominates compared to the negative polarity because of the pulse-like signals are of B type having B-1 and B-3 types of unbalanced polarity. The peak value is diminished because of averaging procedure for dairy monitoring.

of the instrument or electric power shutoff after the main shock by 13:00, March 24. Days from 12 to 23 (vertical dotted lines) are compressed in this figure. In the following statement on time evolution of pulse-like events should be understood under the limit of this period of observation failure. Before the Tohoku Earthquake ("EQ3.11" in this figure), only B type events occurred except for only one pulse of the type A. After the earthquake, on the other hand, types $A$ and $C$ events occurred without type $B$ events.

From these results we can understand the dominance of the positive polarity in diurnal monitoring record on March 9 (Figure 6(d)). On this day there are only B-type variations as seen in Figure 8 . The $B$ type consists of three types, B-1, B-2, and B-3. The B-1 and B-3 types are dominated by positive polarity as seen in Figure 7 . On the other hand B2 is not dominated by neither positive nor negative polarity. The compressed records result in the apparent domination of positive polarity.

As for the B-type variations, there are only several events per day on March 3 and 4. The number of events started to increase on the 7 th, had a prominent peak on the 9th, a pronounced lull on the 10th, and recovered considerably on the morning of 11th until the earthquake occurred. The lull does not mean there are no activity of microcracks. The smaller the threshold is, the more the number of events are. The feature is in agreement with the evolution of space-time distribution of microcracks of rock fracture experiment [4143]. 


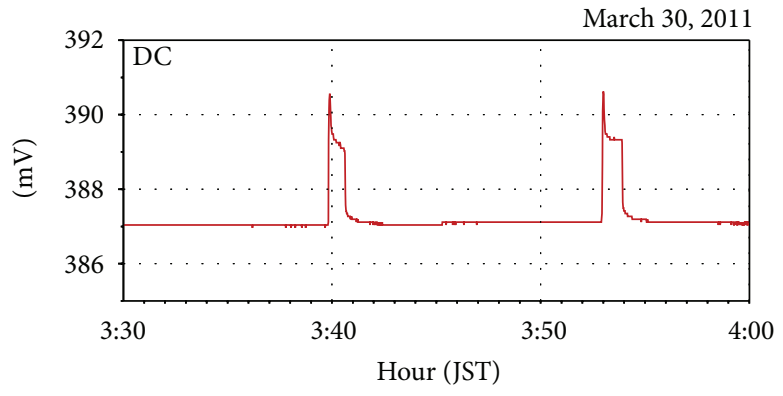

(a) DC: A-type

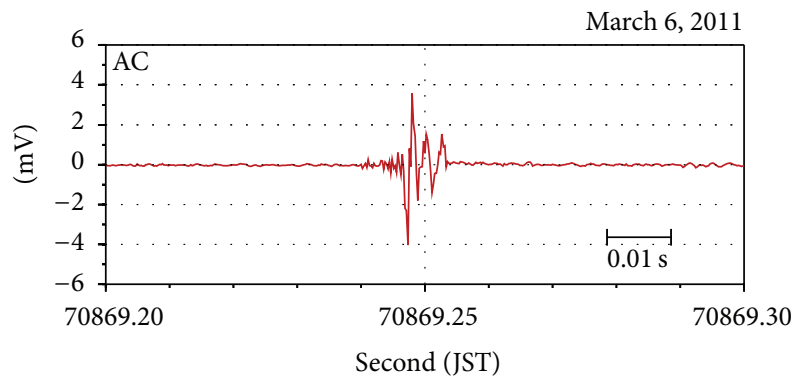

(c) AC: B-2 type

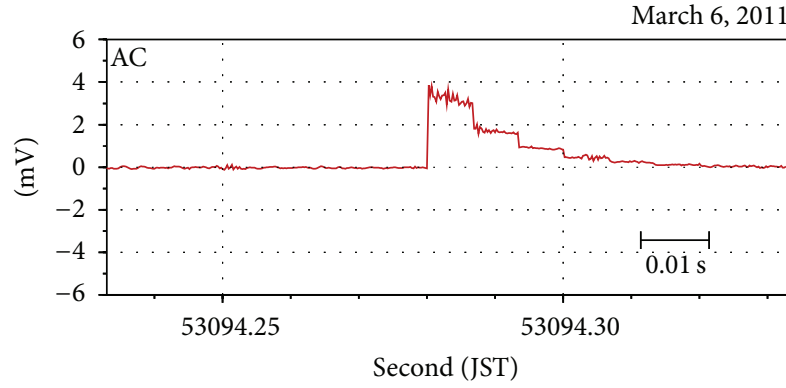

(b) AC: B-1 type

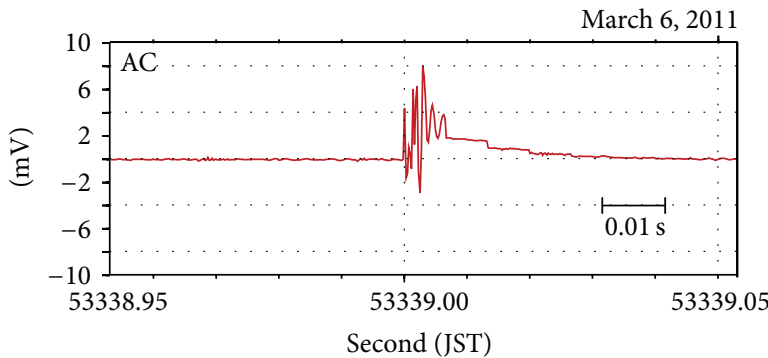

(d) AC: B-3 type

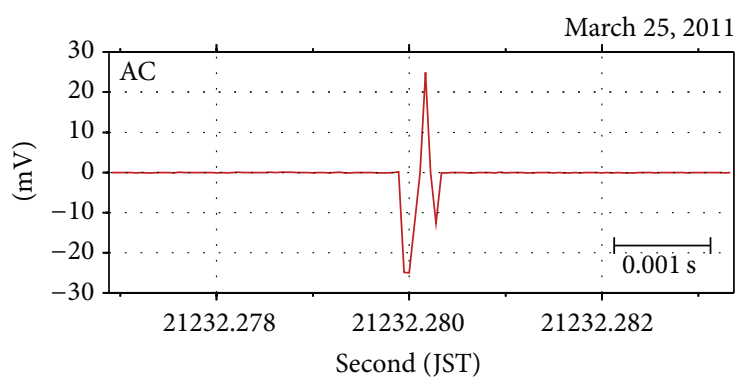

(e) AC: C-type

FIGURE 7: Waveform of the pulse-like particular signals. Every event has large strength compared with noise level with the result of none data filtering. (a) DC band (type A). Type A has a duration of several tens of seconds to several tens of minutes and a height of about 2-3 mV. The form was first identified by the temporally rapid recording at the time of volcanic eruption activities in 1990 at Izu-Oshima [23, 25]. Afterward, we detected similar signals at almost cases of nearby volcanic eruption and seismic swarms [25]. (b) AC band (type B-1). Type B-1 waveform of the pulse-like signals in the AC band. The form is very similar to type A except that it is of smaller duration (several tens of $\mathrm{ms}$ ) and shows several steps in the process of relaxation. There are events both with positive and negative polarities. But the majority events are positive. (c) AC band (type B-2). Type B-2 waveform of the pulse-like signals in the AC band similar with a wave-packet. There is no coda phase, in contrast to seismic waves. A similar pattern was detected in the case of wetted granite specimens with a dominant frequency of $500 \mathrm{kHz}[12,13]$. The S-P time was about $30 \mathrm{~ms}$, suggesting an epicentral distance of $270 \mathrm{~m}$. The absence or very slight appearance of a $\mathrm{P}$ phase indicates an epicentral distance larger than a few $\mathrm{km}$. (d) AC band (type B-3). Type B-3 waveform in the AC band with a waveform compounded by type B-1 and type B-2. There are different degree of compounding. (e) AC band (type C). Type C waveform in the AC band. The waveform is the same as type $\mathrm{B}-2$, but frequency is about $5 \mathrm{kHz}$ and amplitude is very large of $20-30 \mathrm{mV}$, some 10 times larger than those of types A and B types.

The activity of the type B phenomena evolved similarly to those of the acoustic emissions just before the rupture in the rock experiment $[3,13]$ and to those of the foreshocks before main shocks of natural earthquakes (e.g., [4, 6, 7], Varnes [44]). The cumulative number of the foreshock period evolves following the modified Ohmori law. The characteristic evolution has been taken as one of the most direct and clear evidence to identify the nucleation stage in the preparatory process. The accelerated increase of strain causes the particular form of time dependence intrinsic for rupture in the heterogeneous crust $[7,8]$.

Fitting the modified Ohmori law $\left(t_{f}-t\right)^{-n}$ to the cumulative number $N(t)$ (a black curve in Figure 8(b)) of cracks at arbitrary time $t$ (hour) from the final rupture time $t_{f}$ results in the index number to the exponent $n=3.0$ and to $t_{f}=10.9$. The present index number 3.0 is the largest compared with 1.7 for the foreshock [44] and 0.5 for the microcracks in the laboratory experiment [11]. The assumed 

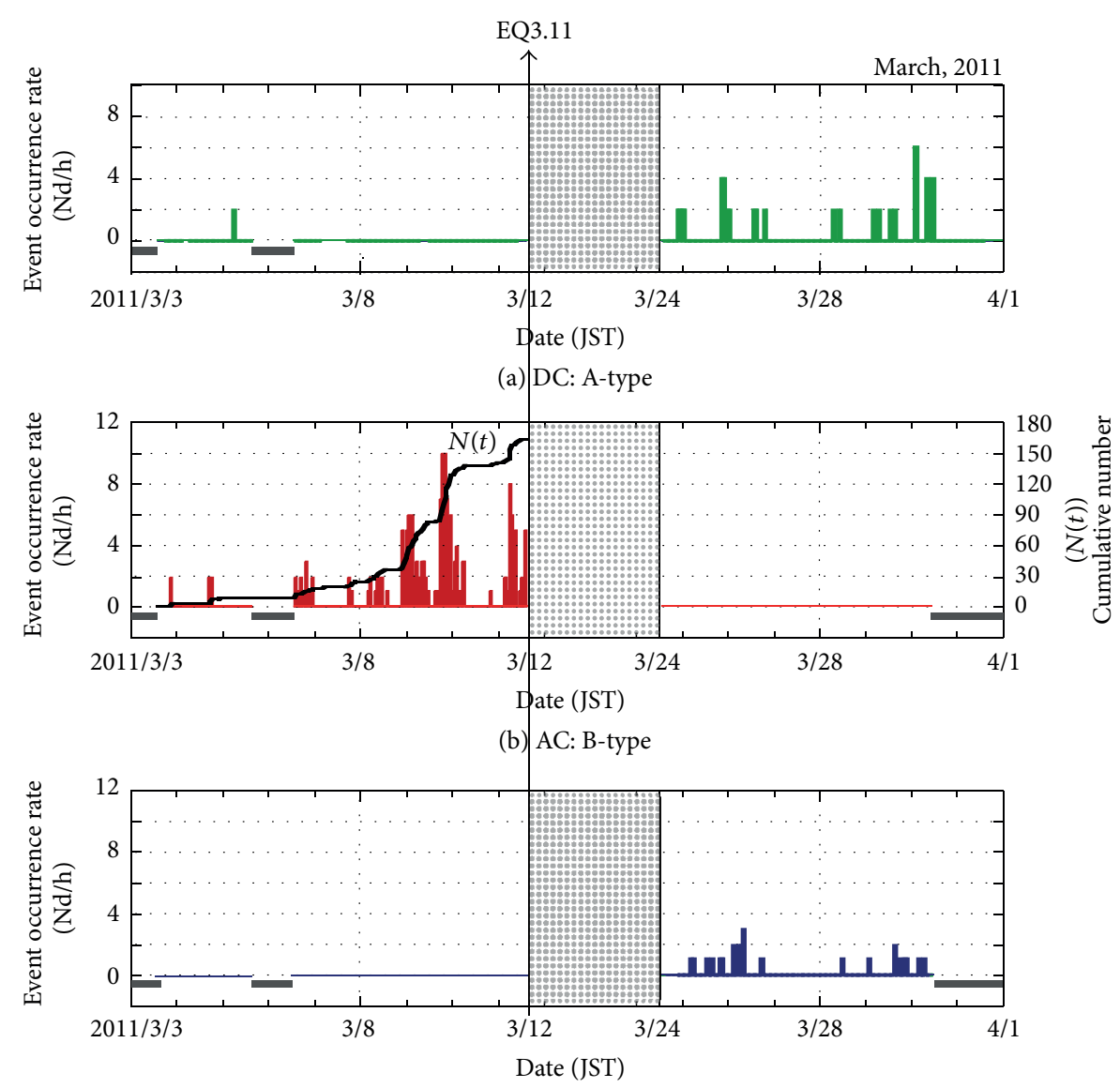

(c) AC: C-type

Figure 8: The Tohoku Earthquake, magnitude 9.0, occurred on March 11, 2011. There are several time periods (grey horizontal line) without data due to logger problems before the main shock and regional electric power shutoff. (a) Time evolution of number of pulse-like signal per hour of type A (green). The unit is shown on the left hand side. Almost all type A variations occurred after the main shock. (b) Time evolution of type B (red) including B-1, B-2, and B-3. The type B variation is suggested to be particularly useful for imminent prediction. The bold continuous curve attached by $N(t)$ shows the cumulative number of B-type variations. The unit of the cumulative number is shown in the right hand side. (c) Time evolution of type $\mathrm{C}$ (blue). This type occurred only after the main shock when the after-effect stage of the seismic cycle.

rupture time $t_{f}=10.9$ agrees satisfactorily with the actual value of 11.6. The characteristic evolution suggests that the microcracks activity is related to the nucleation process of the main shock of the Tohoku Earthquake.

The three types, B-1, B-2, and B-3, occurred in nearly steady percent, 33,46 , and $21 \%$ for the whole period. However the compound type (B-3) decreased its role in the more active period (from 9 to 11, March) with the result of increase of activity of tensile type (B-1) and shear type (B2) (Figure 9). In particular the shear type became dominant from the midnight of the 9th as approaching main rupture. The tendency is also reported in the rock experiment [41-43]. The index number to the exponent of inverse power law $n$ for whole B type is 3.0. Individual fitting of types B-1, B-2, and B-3 to the inverse power law in the period from March 3 till 11:00 March 8 results in $n=2.7,3.0$, and 2.2, respectively. The index numbers to the exponent $n$ do not differ largely in agreement to the near steady percent of each type in

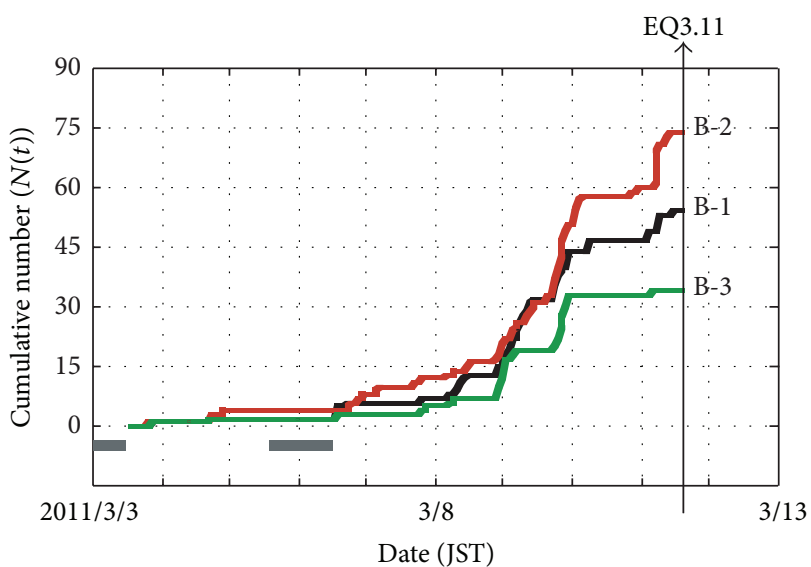

Figure 9: Evolution of the cumulative numbers $N 1(t), N 2(t)$, and $N 3(t)$ for B-1, B-2, and B-3, respectively. B-2 type tend to dominate as approaching to final rupture. But there are no big changes in partial importance in the activity. 


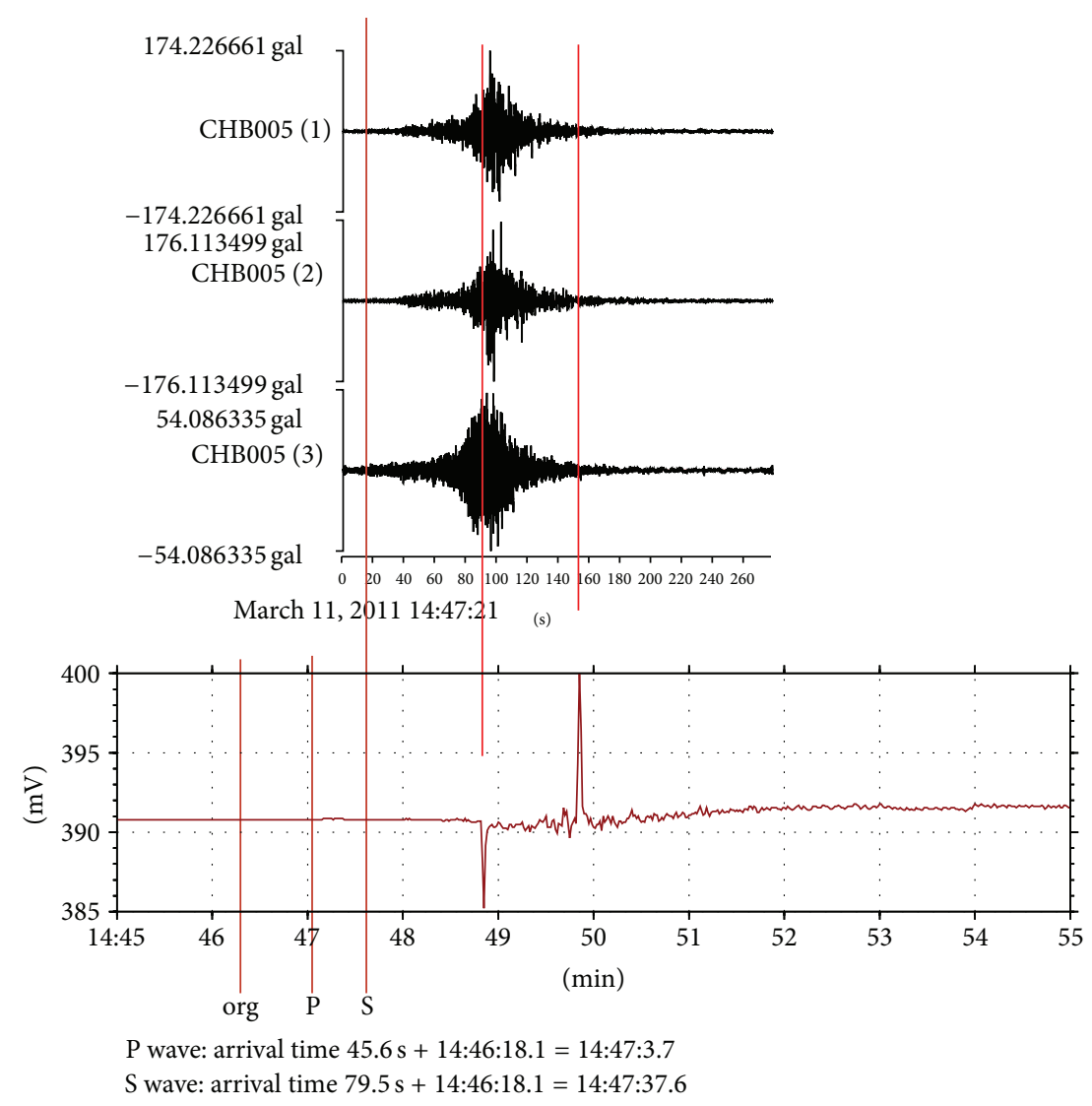

Figure 10: Coseismic electric field variation for the Tohoku earthquake (3.11) at Hasaki (lower sheet) and the strong motion seismograph (UD component) at nearest K-net observation site CHB005 (upper sheet, (1): EW, (2): NS, (3): UD). The vertical line "org", "P", and "S" are origin time of 3.11, $\mathrm{P}$ wave arrival time, and $\mathrm{S}$ wave arrival time at $\mathrm{CHB}$, respectively. There is very faint electric phase corresponding $\mathrm{P}$ arrival time and none phase corresponding to $S$ arrival. The first large negative peak coincides with the peak acceleration and the second prominent peak did not correspond to any phase.

comparison with previous result of 0.5 for rock experiment and 1.7 for foreshocks.

Occurrence of higher frequency events of $\mathrm{C}$ type and low frequency A type after the main shock can be interpreted according to the after effect stage of the seismic cycle. It is supposed that there is a strong adjustment of stress and strain in the rupture area inducing normal closure and shear slips (e.g., Yoshioka and Scholz [45]) causing high-frequency acoustic emissions [11] similar to the C-type microcracks. Around the joints, on the other hand, larger-scale confined water movements are assumed to occur, similarly to cases of seismic swarms and volcanic activities, inducing A-type electric variation of large duration of the order of minutes [25].

\section{Discussion}

\subsection{Correspondence to Foreshocks, Main Shock and Aftershock Period}

4.1.1. Foreshock Period. The main shock occurred on March 11 some $50 \mathrm{~km}$ south of the foreshock at almost the same region as predicted and was made public several years before. There occurred two foreshocks of major class, one of magnitude 7.3 (March 9) and other of 6.8 (March 10). The microcracks might be imagined to be associated with the foreshocks that occurred two days before the Tohoku earthquake when the activity of microcracks was largest. There were no coseismic electric variations corresponding to these foreshocks themselves as detected previously in 2002 [32]. And, the detection distance of the characteristic electric variation was estimated to be at most 100 kilometers $[25,32]$. Additionally the epicentral distances of these $f$ foreshocks from the observation site, Hasaki, are about $300 \mathrm{~km}$ northeast (Figure 4, Suzuki et al. [33]). So that we suppose that the Btype variations are not related to the foreshocks.

4.1.2. Main Shock. It has been revealed that the great rupture consist of three subevents: main asperity and subsequent two events [33]: first in the northern part, second succeeded southward, and third propagated from southwest to north (e.g., [33]).

Anomalous electric signals corresponding to main shock are shown in the lower sheet of Figure 10. And the strong motion records of K-NET (CHB005) near Hasaki are in the upper sheet. There are coseismic variations, but 
the prominent peak appeared at around the peak acceleration and the second peak with opposite polarity appeared about one minutes later. But there are no significant electric variations in correlation with the origin time and $\mathrm{P}, \mathrm{S}$ wave arrival time ("org", "P", and "S", in the figure, resp.) as reported in the previous reports [32]. It may be caused by complex rupture comprised of three stages [33]. We note that the time scale of the electric variation related to main shock is of a few minutes compared several tens $\mathrm{ms}$ of $\mathrm{B}$ and several $\mathrm{ms}$ of C-type cracks. On the other hand, the maximum electric strength corresponding to the main shock is $5 \mathrm{mV}$ nearly the same as those of microcracks.

The fault displacement shows a simple distribution [33] without any trace to separate rupture blocks. We can think that the whole fault including the southwestern region (Figure 4) ruptured simultaneously. The time evolution of the B-type activity suggests intimate relation to the main shock through Omori's law (Figure 8). On the basis of these evidences, we can suppose that the microcracks of B type are related to the nucleation process of the main shock which induced the fault movement amounting several centimeters near the observation site.

4.1.3. Aftershock Period. Aftershock occurred in an extensive area in and around the main rupture of 3.11. During 3 weeks after the main shock there occurred as many as 427 aftershocks with a magnitude larger than 5.0 in and around the rupture zone of 3.11. In this period there occurred Aand C-type variations of highest frequency of some $5 \mathrm{kHz}$ (Figure 8). After the main shock there were no events of type $B$ and none of coseismic variations association with aftershocks. The increased strength of AE related to the natural earthquakes after the main shock [19-21] might be caused by this kind of emission.

4.2. Radio Wave Emission. Electromagnetic emission observation in VLF bands has been widely conducted to investigate the nucleation process. It is generally reported that there are considerable correlation between occurrence time of earthquakes and those of emission: the strength of electromagnetic emission increase before and/or after earthquake (e.g., [20, 21] Fujinawa et al. [46], Parrot et al. [47]). Some reports suggest that $\mathrm{MHz}$ emission occur several weeks before and the VLF emission occurs only in the nucleation period [8, 9 , 17] in contrary to the appearance of VLF type variation (C type) in this report. We do not have data to discuss the $\mathrm{MHz}$ event because of the detection frequency that is less than about $10 \mathrm{kHz}$. As for VLF emission we need supplementary data such as location information $[46,47]$ to know whether we are treating the same phenomena or not.

4.3. Detection Distance. The AE monitoring for rock burst is usually conducted with the spacing of several tens of meter (e.g., Hasegawa et al. [48]) suggesting low value of Q factor of about 3. They found there are two kinds of AEs, lower frequency ones of several hundred $\mathrm{Hz}$ and several $\mathrm{kHz}$ for monitoring rock burst for tunnel works. These two dominant frequency bands seem to correspond to those of B type and of
C type of our observation. But we need more investigation at present to determine if there are any intrinsic reasons or not.

The detection distance of seismoelectromagnetic signals (SES) by the borehole antenna is suspected to be some three orders much larger than that of the acoustic emission method $[25,32]$. Here we do not concern the radio wave in the atmosphere: they can propagate surrounding the earth. The long detection distance of the electric signal detected from the origin time [32] was assumed to be due to the high resolving power of the observation system and/or to the small attenuation rate of the seismoelectric variation itself. Another possibility is the conversion of the seismic wave to electric mode at the conductivity contrast (e.g., [31, 36], Gershenzon and Bambakidis [49]). The converted waves can propagate long distance because of power law dissipation compared with the exponential dissipation. The effective propagation speed on the order of $100 \mathrm{~km} / \mathrm{s}$ or possibly electromagnetic speed in the earth is much larger than that of the diffusion spreading for the realistic conductivity of $0.1-0.001 \mathrm{Sm}^{-1}$. We can expect that the microcracks can be detected at a larger distance by the electromagnetic measurement of high quality than by the ordinary technique using acoustic emission.

4.4. Generation Mechanism. Fujinawa et al. [32] reported the remote detection of the Earth's electric field variations from the start of fault rupturing at about $100 \mathrm{~km}$ from the fault region using borehole antenna. Investigation of generation mechanism of the seismoelectromagnetic signals (SES) (e.g., $[36,49])$ in the field indicates that the dominant mechanism is the electrokinetic effect compared with the piezomagnetic, piezoelectric, nonclassical piezoelectric, and induction effects [32]. A simple model of electric variation propagation in porous media using the basic Maxwell equations and electrickinetic interaction effects $[25,26]$ show that detective length reaches to several tens of kilometers.

The characteristic electric field variation induced by cracks through electrokinetic mechanism can be more systematically discussed on the basis of formulation of Pride [50] and Haartsen and Pride [51]. It has been shown by analytical approaches and numerical simulations that there are four kinds of wave, slow $\mathrm{P}$ wave and fast $\mathrm{P}$ wave (ordinary $\mathrm{P}$ wave), $S$ wave (ordinary $S$ wave), and electromagnetic wave (EM). The theory is extended to no-Newtonian fluid (Araji et al. [52]), and numerous application have been conducted on the interaction of seismic wave and electric field in the porous media (e.g., [52], Schoemaker et al. [53]). Han [37] tried to interpret the ULF geomagnetic variation induced by the slow slip by using formula of Pride [50] and fault model of $\mathrm{Gao}$ and $\mathrm{Hu}$ [54]. The A-type variation after the main shock can be interpreted as the electric field variation induced by slow movement of confined fluid though normal closure or opening in the process of rearrangement of strain or stress.

4.5. Phases. There are some events in B types which have clear primary phase preceding main phase as illustrated in Figure 11 . The primary wave $(\mathrm{P})$ has very small amplitude of some one-tenth to the secondary phase $(\mathrm{S})$, and majority of events have no trace of primary wave. The feature is similar to 
the coseismic variation with the ordinary seismic wave [32]. The tendency is the same for the whole cases of detections in the field. But the feature is contrary to the simulation results (e.g., [51, 54], Ren et al. [55]). The electric strength induced by $\mathrm{P}$-wave is much larger than that by $\mathrm{S}$-wave. We can suppose that the tendency may change according to specimens of rocks $[54,55]$ or distribution of contrasts of sediment. Electromagnetic mode (EM) has been confirmed in the laboratory and simulation experiments $[52,53]$. In the present observation there are occasionally small forerunners as illustrated in Figure 11. The arrival time difference E$S$ corresponds to the electric wave propagation velocity of some 900 times $S$ wave velocity. But the EM phase is too vague to confirm the EM mode. The slow $\mathrm{P}$ wave has very small velocity of several $\mathrm{m} / \mathrm{s}[52,53]$ and has too slight strength hardly recorded in the present ability of recording in agreement with the numerical simulation results that the independently traveling EM. The wave has strength three order.smaller than those by seismic waves $[54,56]$.

The S-P time of events A20110308_04h49m03s (Figure 11), A20110308_23h55m23s, A20110309_00h09m14s, and A20110309_01h51m25s (Table 1 in the appendix) are 20, 25, 17 , and $14 \mathrm{~ms}$ corresponding to $160,200,133$, and $109 \mathrm{~m}$ of epicentral distances, respectively. But almost all events have no or slight appearance of $\mathrm{P}$ phase. It is supposed that $\mathrm{S}$ $\mathrm{P}$ times are larger than $50 \mathrm{~ms}$ corresponding to epicentral distance larger than a few $\mathrm{km}$.

4.6. Complex Events. Just before the main shock occurrence there appeared some events superposed by numerous small events as illustrated in Figure 12. The relative occurrence time is considerably different with the different phase of the main events. It suggests that small event increased to occur in the neighborhood of larger events. Another phenomenon is that there appeared long chain of small events. We suspect that microcracks activity has changed at the last stage of nucleation phase corresponding to intermittent criticality causing fluctuation of cumulative curve fitted to the Ohmori's law. These complex and long chain events occurred only on 2 days before the main shock without appearance on 10th, 11th, March, that is, in the lull period of microcracks activity. The phenomena may be related with the intermittent criticality [6].

4.7. Intermittent Criticality. There appeared undulation of microcracks activity after the most active period around 9th March. Similar phenomena have been reported in laboratory experiments and field observation (e.g., [7-9, 23] Huang et al. [55]). The undulation has been suggested to reflect the intermittent criticality indicating entering another phase of nucleation to interpret the superposed undulation of the seismic activity as the case of the Loma Prieta Earthquake [7]. Another example concerns rapid change of magnetotelluric impedance (Honkura et al. [57]) some half hour before the Izmit earthquake (2000) in Turkey. Eftaxias and his group $[8,9]$ used their VLF radio wave emissions to investigate nucleation stage using their observation evidence of disappearance of the emission just before the main shock. They also

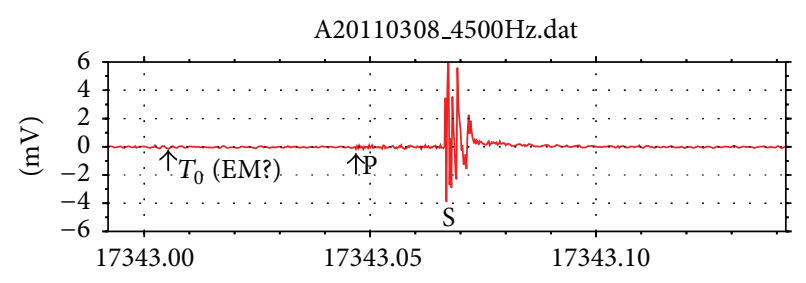

(s)

FIGURE 11: Sample waveform of events having the primary phase ("P" in the figure) before the main phase (" $\mathrm{S}$ " in the figure). The EM mode is suspected at around the origin time $T_{0}(\mathrm{EM})$ considering very large speed of more than one hundred times that of fast $P$ phase.

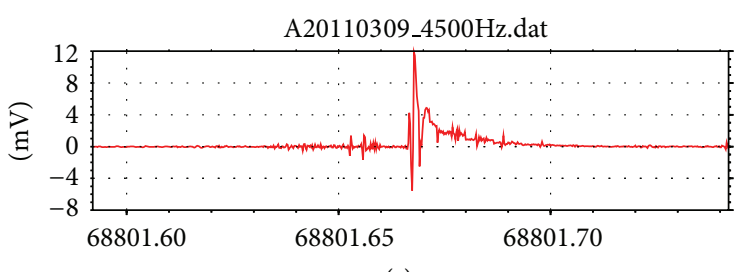

(s)

FIgURE 12: A sample waveform of the event of B-2 superimposed with many small events suggesting connection of groups of small scale cracks. This type appeared only on the most active day of microcrack, that is, on 9th March (Figure 8).

tried to explain the IC based on fracture dynamics, critical phenomena, and percolation theory.

There is a disagreement in the VLF activity between some of previous results and present cases. It is reported that there is no VLF after the main shock in the report of $[8,9]$. On the contrary we detect the C-type variation in frequency bands of VLF. We suppose that present events are suggested to be different from to the so-called VLF emission as those reported in $[46,47]$ and [7-9]. We need supplementary data to compare different observational results. For instance the location of the VLF wave rarely agrees with the epicentral region $[46,47]$.

Here we present the case that the activity is dominated by the $\mathrm{B}$ types in the final stage superimposed numerous complex microcracks, which suggests appearance of different regime of the nucleation process but without drastic phase transition.

4.8. Asperity. We suggest that the microcracks occurred in the southeastern peripheral of the great rupture of length $500 \mathrm{~km}$ in relation to the nucleation stage of the main rupture. We can imagine that the accelerated strain accumulation is not restricted to the so-called asperity region at around the epicenter of foreshock or main shock (Figure 4). Significant accumulation is suggested to occur at the whole area of future rupture with the result of microcrack activity though there is difference in the intensity or type of cracks. Extensive monitoring of the microcracks can reveal these points to provide a clue to answer this question. 
TABle 1: Catalog B-type Pulse 2011-03-03 2011-03-11.

\begin{tabular}{|c|c|c|c|c|c|c|}
\hline Number & Second & Hour & Type & Strength $(\mathrm{mV})$ & Duration $(\mathrm{ms})$ & Comment \\
\hline \multicolumn{7}{|c|}{ 3-March } \\
\hline 1 & 74089.15 & 20.58 & B-2 & -3.5 & 40 & P phase? \\
\hline 2 & 76994.65 & 21.39 & B-3 & -5.5 & 30 & P phase \\
\hline 3 & 77752.56 & 21.60 & B-1 & 2 & 25 & \\
\hline \multicolumn{7}{|c|}{ 4-March } \\
\hline 4 & 63758.70 & 17.71 & B-3 & 11.5 & 30 & \\
\hline 5 & 64522.10 & 17.92 & B-2 & 5 & 40 & \\
\hline 6 & 65485.30 & 18.19 & B-2 & -11.5 & 10 & \\
\hline 7 & 65937.20 & 18.32 & B-2 & 12 & 10 & \\
\hline 8 & 81148.30 & 22.54 & B-2 & -3.0 & 10 & P phase \\
\hline \multicolumn{7}{|c|}{ 6-March } \\
\hline \multicolumn{7}{|c|}{ Till 14:00 (no-data) } \\
\hline 8 & 50571.1 & 14.05 & B-1 & 2 & 30 & \\
\hline 9 & 53094.25 & 14.75 & B-1 & 3.8 & 40 & \\
\hline 10 & 53336.8 & 14.82 & B-1 & 16.0 & 40 & \\
\hline 11 & 64179.30 & 17.83 & B-1 & 3.3 & 40 & Clear P phase \\
\hline 12 & 65995.55 & 18.33 & B-2 & 6.5 & 14 & \\
\hline 13 & 70869.25 & 19.69 & B-2 & 3.5 & 20 & \\
\hline 14 & 75902.15 & 21.08 & B-2 & 9.5 & 25 & \\
\hline 15 & 83206.30 & 23.11 & B-3 & -2.2 & 40 & \\
\hline 16 & 84237.55 & 23.40 & B-2 & 8.3 & 25 & Subevents \\
\hline \multicolumn{7}{|c|}{ 7-March } \\
\hline 16 & 16950.85 & 4.71 & B-2 & 2 & 15 & \\
\hline 17 & 20103.65 & 5.58 & B-2 & 3.3 & 12 & \\
\hline 18 & 64481.80 & 17.91 & B-2 & 2.1 & 13 & \\
\hline 19 & 68579.95 & 19.05 & B-1 & 2.2 & 37 & \\
\hline 20 & 69144.05 & 19.21 & B-3 & 4.2 & 40 & \\
\hline 21 & 69559.45 & 19.32 & B-2 & 2.1 & 9 & \\
\hline 22 & 79177.40 & 21.99 & B-3 & 7.9 & 45 & \\
\hline \multicolumn{7}{|c|}{ 8-March } \\
\hline 23 & 17343.05 & 4.82 & B-2 & 8.0 & 35 & P, S phase \\
\hline 24 & 21232.45 & 5.90 & B-3 & 12.4 & 45 & P, S phase \\
\hline 25 & 21512.30 & 5.98 & B-1 & 4.1 & 37 & HF. At 1st step \\
\hline 26 & 26099.85 & 7.25 & B-2 & 2.1 & 4 & \\
\hline 27 & 26871.50 & 7.46 & B-3 & 5.7 & 37 & \\
\hline 28 & 31388.05 & 8.72 & B-1 & 7.0 & 45 & Subevent in coda \\
\hline 29 & 33307.20 & 9.25 & B-1 & 4.1 & 60 & P, S phase? \\
\hline 30 & 33624.30 & 9.34 & B-1 & 8.5 & 60 & \\
\hline 31 & 39163.85 & 10.88 & B-1 & 5.1 & 43 & \\
\hline 32 & 39727.80 & 11.04 & B-1 & 4 & 40 & \\
\hline 33 & 42297.30 & 11.75 & B-2 & 2 & 7 & \\
\hline 34 & 44458.00 & 12.35 & B-2 & 2 & 15 & \\
\hline 35 & 75881.30 & 21.08 & B-2 & 2.2 & 8 & \\
\hline 36 & 79821.30 & 22.17 & B-3 & 5.8 & 30 & \\
\hline 37 & 80090.35 & 22.25 & B-3 & -3.8 & 45 & \\
\hline 38 & 80203.15 & 22.28 & B-2 & 6.2 & 20 & \\
\hline 39 & 82117.00 & 22.81 & B-3 & 11.5 & 50 & \\
\hline 40 & 82234.60 & 22.84 & B-1 & 3 & 40 & \\
\hline 41 & 82617.35 & 22.95 & B-3 & 5.8 & 40 & \\
\hline 42 & 83904.35 & 23.31 & B-2 & 2.7 & 10 & \\
\hline 43 & 83904.40 & 23.31 & B-2 & 5 & 10 & \\
\hline
\end{tabular}


TABle 1: Continued.

\begin{tabular}{|c|c|c|c|c|c|c|}
\hline Number & Second & Hour & Type & Strength $(\mathrm{mV})$ & Duration (ms) & Comment \\
\hline 44 & 85307.20 & 23.7 & B-2 & 4.1 & 10 & \\
\hline 45 & 85885.95 & 23.86 & B-2 & -11.7 & 25 & \\
\hline 46 & 86122.75 & 23.92 & B-3 & -2.8 & 30 & $\mathrm{P}, \mathrm{S}$ phase? \\
\hline 47 & 86738.30 & 24.09 & B-2 & 2.2 & 10 & \\
\hline 48 & 86953.40 & 24.15 & B-2 & 4.2 & 15 & \\
\hline 49 & 87379.20 & 24.27 & B-2 & 2.1 & 10 & \\
\hline 50 & 87590.00 & 24.33 & B-2 & 6.0 & 10 & \\
\hline 51 & 89027.35 & 24.73 & B-1 & 5 & 45 & \\
\hline \multicolumn{7}{|c|}{ 9-March } \\
\hline 52 & 2493.70 & 0.69 & B-1 & 2.5 & 47 & \\
\hline 53 & 3817.85 & 1.06 & B-2 & 3.7 & 33 & High freq.com at 1 st step $1.5 \mathrm{kHz}$ \\
\hline 54 & 4109.35 & 1.14 & B-3 & 8.3 & 43 & \\
\hline 55 & 5327.10 & 1.48 & B-3 & 6 & 44 & \\
\hline 56 & 5374.60 & 1.49 & B-1 & 2.2 & 32 & \\
\hline 57 & 6221.80 & 1.73 & B-3 & 2.1 & 40 & \\
\hline 58 & 6272.40 & 1.74 & B-3 & 3.5 & 50 & Complex \\
\hline 59 & 6454.95 & 1.79 & B-3 & 5.4 & 60 & \\
\hline 60 & 6684.75 & 1.86 & B-3 & 8.9 & 30 & $\mathrm{P}, \mathrm{S}$ phase? \\
\hline 61 & 7091.50 & 1.97 & B-3 & 18.3 & 40 & $\mathrm{P}, \mathrm{S}$ phase? \\
\hline 62 & 8501.15 & 2.36 & B-1 & 3 & 30 & \\
\hline 63 & 11404.10 & 3.17 & B-1 & 3.5 & 35 & P, S phase? \\
\hline 64 & 12040.80 & 3.34 & B-1 & 3.5 & 40 & $\mathrm{P}, \mathrm{S}$ phase? \\
\hline 65 & 12185.25 & 3.38 & B-1 & 8.0 & 20 & \\
\hline 66 & 12983.65 & 3.61 & B-1 & 7.5 & 50 & P, S phase? \\
\hline 67 & 14067.05 & 3.91 & B-2 & 6.3 & 30 & $\mathrm{P}, \mathrm{S}$ phase? \\
\hline 68 & 14206.80 & 3.95 & B-1 & 5 & 40 & $\mathrm{P}, \mathrm{S}$ phase? \\
\hline 69 & 16891.85 & 4.69 & B-3 & 11.3 & 30 & $\mathrm{P}, \mathrm{S}$ phase? \\
\hline 70 & 16892.00 & 4.69 & B-2 & 4.1 & 10 & \\
\hline 71 & 19113.05 & 5.31 & B-2 & 4.5 & 10 & $\mathrm{P}, \mathrm{S}$ phase? \\
\hline 72 & 19198.05 & 5.33 & B-1 & 3 & 35 & $\mathrm{P}, \mathrm{S}$ phase? \\
\hline 73 & 21171.70 & 5.88 & B-1 & 2 & 30 & \\
\hline 74 & 21657.55 & 6.02 & B-1 & 3.5 & 40 & \\
\hline 75 & 22136.65 & 6.15 & B-1 & 4 & 35 & \\
\hline 76 & 26479.25 & 7.36 & B-1 & 3.5 & 35 & \\
\hline 77 & 27832.15 & 7.73 & B-1 & 2.2 & 40 & \\
\hline 78 & 29191.10 & 8.11 & B-1 & 3 & 30 & \\
\hline 79 & 30824.20 & 8.56 & B-2 & 2.2 & 20 & \\
\hline 80 & 31511.55 & 8.75 & B-2 & 2.2 & 10 & \\
\hline 81 & 33641.20 & 9.34 & B-2 & 4.3 & 10 & \\
\hline 82 & 33649.35 & 9.35 & B-1 & 2 & 35 & \\
\hline 83 & 35323.25 & 9.81 & B-1 & 4 & 45 & \\
\hline 84 & 37181.60 & 10.33 & B-2 & -2.1 & 10 & \\
\hline 85 & 39193.76 & 10.89 & B-2 & 4 & 10 & \\
\hline 86 & 42674.60 & 13.8 & B-2 & 4 & 40 & \\
\hline 87 & 54068.55 & 15.02 & B-2 & 2 & 10 & \\
\hline 88 & 55135.70 & 15.32 & B-1 & 11.3 & 40 & \\
\hline 89 & 66156.10 & 18.38 & B-2 & -5.1 & 10 & \\
\hline 90 & 66775.25 & 18.55 & B-2 & 5.1 & 30 & \\
\hline 91 & 67365.35 & 18.43 & B-1 & 4 & 40 & \\
\hline 92 & 67574.65 & 18.77 & B-2 & 3 & 27 & Complex \\
\hline 93 & 67651.80 & 18.79 & B-2 & 2.8 & 10 & \\
\hline
\end{tabular}


TABle 1: Continued.

\begin{tabular}{|c|c|c|c|c|c|c|}
\hline Number & Second & Hour & Type & Strength $(\mathrm{mV})$ & Duration (ms) & Comment \\
\hline 94 & 67766.85 & 18.82 & B-1 & 3.7 & 33 & \\
\hline 95 & 67999.75 & 18.89 & B-1 & 3 & 30 & Most complex \\
\hline 96 & 68063.10 & 18.91 & B-3 & 10.8 & 45 & \\
\hline 97 & 68211.65 & 18.95 & B-2 & 5 & 15 & Most complex \\
\hline 98 & 68801.6 & 19.11 & B-3 & 11.9 & 60 & \\
\hline 99 & 69211.45 & 19.23 & B-1 & 3.5 & 35 & \\
\hline 100 & 69769.60 & 19.38 & B-3 & -4.0 & 35 & \\
\hline 101 & 70573.30 & 19.6 & B-1 & 3.1 & 35 & \\
\hline 102 & 71162.05 & 19.77 & B-2 & 2.9 & 28 & Complex \\
\hline 103 & 71496.80 & 19.86 & B-1 & 4.1 & 50 & Subevent \\
\hline 104 & 71694.70 & 19.92 & B-2 & 3.5 & 10 & \\
\hline 105 & 71939.50 & 19.98 & B-2 & 2.8 & 10 & \\
\hline 106 & 72573.75 & 20.16 & B-3 & -4.2 & 25 & Complex \\
\hline 107 & 72754.65 & 20.21 & B-3 & -16.0 & 40 & \\
\hline 108 & 73382.65 & 20.38 & B-2 & 4 & 10 & \\
\hline 109 & 73409.05 & 20.39 & B-2 & 2.2 & 8 & \\
\hline 110 & 73619.15 & 20.45 & B-1 & 3 & 40 & Complex \\
\hline 111 & 73893.35 & 20.53 & B-2 & 3.9 & 10 & \\
\hline 112 & 74918.70 & 20.81 & B-3 & 9.2 & 35 & \\
\hline 113 & 75750.80 & 21.04 & B-1 & -4.0 & 30 & Subevent \\
\hline 114 & 76353.05 & 21.21 & B-2 & 9.7 & 10 & Subevent \\
\hline 115 & 76732.30 & 21.31 & B-2 & 3.9 & 10 & Subevent \\
\hline 116 & 77958.25 & 21.66 & B-2 & 4.3 & 15 & \\
\hline 117 & 78709.60 & 21.86 & B-3 & 10.5 & 40 & \\
\hline 118 & 78908.15 & 21.92 & B-2 & -7.6 & 10 & Typical B-2 type \\
\hline 119 & 79258.25 & 22.02 & B-3 & 2 & 33 & P? subevent? \\
\hline 120 & 80042.45 & 22.23 & B-2 & 2.1 & 9 & P? subevent? \\
\hline 121 & 82451.20 & 22.9 & B-2 & 4 & 10 & \\
\hline 122 & 82632.30 & 22.95 & B-3 & 6.5 & 30 & P? subevent? \\
\hline 123 & 83138.70 & 23.09 & B-2 & -10.1 & 10 & \\
\hline 124 & 84541.40 & 23.48 & B-3 & 11.0 & 30 & \\
\hline 125 & 84795.30 & 23.55 & B-3 & 6.5 & 35 & \\
\hline 126 & 84841.35 & 23.57 & B-1 & 4 & 30 & Subevent \\
\hline 127 & 85341.90 & 23.71 & B-1 & 4.4 & 34 & \\
\hline 128 & 85352.70 & 23.71 & B-2 & 6 & 10 & \\
\hline 129 & 85374.55 & 23.72 & B-1 & 3 & 45 & \\
\hline 130 & 87677.00 & 24.35 & B-1 & 5 & 38 & P phase? \\
\hline 131 & 88837.15 & 24.68 & B-2 & 3.1 & 10 & \\
\hline \multicolumn{7}{|c|}{ 10-March } \\
\hline 132 & 3800.15 & 1.06 & B-2 & 4.1 & 20 & P phase? \\
\hline 133 & 4262.10 & 1.18 & B-2 & 2.2 & 22 & P phase? \\
\hline 134 & 5869.60 & 1.63 & B-2 & 3.7 & 15 & Subevent \\
\hline 135 & 7020.15 & 1.95 & B-2 & 2.5 & 15 & \\
\hline 136 & 7870.35 & 2.19 & B-2 & 2 & 10 & \\
\hline 137 & 8116.80 & 2.25 & B-2 & 2 & 10 & \\
\hline 138 & 17156.75 & 4.77 & B-3 & 12.0 & 40 & \\
\hline 139 & 24115.35 & 6.70 & B-1 & 5 & 50 & \\
\hline 140 & 24348.45 & 6.76 & B-1 & 5.5 & 37 & \\
\hline 141 & 75609.20 & 21.00 & B-2 & 10.5 & 35 & P phase? \\
\hline 142 & 84056.55 & 23.35 & B-2 & 2 & 15 & \\
\hline
\end{tabular}


TABle 1: Continued.

\begin{tabular}{|c|c|c|c|c|c|c|}
\hline Number & Second & Hour & Type & Strength $(\mathrm{mV})$ & Duration (ms) & Comment \\
\hline \multicolumn{7}{|c|}{ 11-March } \\
\hline 143 & 13276.85 & 3.69 & B-1 & 3.5 & 45 & \\
\hline 144 & 13400.30 & 3.72 & B-1 & 2 & 35 & \\
\hline 145 & 15506.5 & 4.31 & B-3 & 4.2 & 45 & $\mathrm{P}, \mathrm{S}$ phase \\
\hline 146 & 18325.85 & 5.09 & B-2 & 2.2 & 20 & $\mathrm{P}, \mathrm{S}$ phase \\
\hline 147 & 21801.45 & 6.06 & B-2 & 4 & 20 & $\mathrm{P}, \mathrm{S}$ phase \\
\hline 148 & 22395.30 & 6.22 & B-2 & 7.0 & 10 & \\
\hline 149 & 22503.65 & 6.25 & B-2 & 8.0 & 10 & \\
\hline 150 & 22628.50 & 6.29 & B-2 & 3 & 10 & \\
\hline 151 & 22891.70 & 6.36 & B-2 & -7.0 & 15 & \\
\hline 152 & 23432.95 & 6.51 & B-2 & 5.5 & 10 & P-S $40 \mathrm{~ms}$ \\
\hline 153 & 23485.85 & 6.52 & B-2 & -11.0 & 35 & \\
\hline 154 & 25421.75 & 7.06 & B-2 & 4 & 15 & $\mathrm{P}, \mathrm{S}$ phase \\
\hline 155 & 25658.20 & 7.13 & B-1 & 12.5 & 35 & \\
\hline 156 & 27287.35 & 7.58 & B-1 & 2 & 35 & \\
\hline 157 & 27319.50 & 7.59 & B-2 & -8.5 & 10 & \\
\hline 158 & 27385.00 & 7.61 & B-1 & 2 & 35 & $\mathrm{P}, \mathrm{S}$ phase \\
\hline 159 & 28639.15 & 7.96 & B-1 & 3.2 & 36 & \\
\hline 160 & 34295.7 & 9.53 & B-2 & 2.6 & 20 & \\
\hline 161 & 34564.55 & 9.60 & B-2 & 4.1 & 10 & $\mathrm{P}, \mathrm{S}$ phase \\
\hline 162 & 36804.60 & 10.22 & B-2 & 2.5 & 10 & \\
\hline 163 & 45290.80 & 12.58 & B-1 & 2 & 35 & $\mathrm{P}, \mathrm{S}$ phase \\
\hline
\end{tabular}

\section{Conclusion}

We showed that the electromagnetic method can detect microcracks preceding natural earthquakes by a special underground antenna as an alternative to acoustic emission measurement. The nucleation stage of a crustal rupture can be identified by monitoring the electric field variations focusing on particular waveforms in the selected frequency ranges. These pulse-like phenomena are suggested to be plausible precursors for an imminent prediction.

Earthquakes are understood to be fracture of crustal rocks or stick slip of neighboring blocks. Preshocks occur generally in the rupture preparatory stage, and the activity has accelerated phase preceding main rupture. But that feature appears when averaged for many earthquakes. Preshock activity of individual earthquake is less regular to be used for confident predictive purpose.

Microcracks are always detected in the nucleation stage of accelerated deformation in almost all laboratory experiments. There are several efforts to investigate microcracks related to natural earthquakes by means of acoustic emission measurements. But they have not succeeded to find particular phenomena to identify the nucleation stage though the increase of acoustic emission intensity has been detected just half a day before and after main shocks.

We have been observing electromagnetic field changes for investigating the field characteristics related to earthquake activity and seismic wave in order for earthquake prediction and for application for early warning by using special underground antenna. The measurement method has been proved to be robust to the natural and man-made noises by observational investigation since 1989. Here we show that the instrument could detect microcracks appearing in the nucleation stage of the Tohoku Earthquake. Whole large pulse-like variations were grouped into three $(\mathrm{A}, \mathrm{B}$, and $\mathrm{C})$ by frequency and waveforms and found to characterize different phases of the earthquake occurrence, the preparation, main shock, and after shock processes. Those variations are grouped by time constants: type A with duration of several to several ten minutes just the same as the pulse-like signals detected previously at the time of volcanic eruption and seismic swarms, B of several hundred $\mathrm{Hz}$, and $\mathrm{C}$ of several $\mathrm{kHz}$. The A type was identified in the early stage of observation at the time of volcanic eruption in 1992 and has been suggested to be induced by seismic swarms and volcanic eruption. The $B$ type variations are subgrouped into three waveform: type B-1 of similar to the GUV except in the stepped decay in the relaxation phase after sharp rise, type B- 2 of wave packet similar to acoustic emission, and type B-3 of superposition of B-1 and B-2. Different types of electric waveforms of the $B$ type are suggested to correspond to crack rupture modes of tensile and shear and to be generated by confined water movement through the electrokinetic effects on the ground of previous investigations on laboratory experiments. The earthquake preparation period is characterized by the appearance of characteristic microcracks: beginning period of the nucleation period is characterized by rare occurrence of A types, nucleation period is by B types and particular evolution of the subgrouped types. The second kind of cracks (B type) is shown to occur only in the nucleation period: 
activity increases sharply before the earthquake following the modified Ohmori's law. A and C occur at the stress arrangement period after the main shock. Field monitoring of microcracks activity by EM method is shown to be practically possible to investigate the nucleation stage providing a breakthrough for the short term prediction method.

\section{Appendix}

\section{Waveform Catalog of B-Type Variations}

We picked up 224 events under the condition of larger event than three times of back ground level. All of the events are grouped in one of three groups without any undefined ones originating from urban and natural noises. It is very unique point of e-field observation by the borehole antenna. Among the three types the $\mathrm{B}$ type is the most interesting from the point of view of identification of the nucleation stage of natural earthquake. We present a catalog of whole B-type events consisting of 163 events. Almost all events are compounded by B-1 and B-2. But events containing dominantly the tensile mode are grouped into B-1, and the shear modes are grouped into B-2. The grouping is done not quantitatively but qualitatively. The results of grouping exist in Table 1. The Table is constructed as follows:

(1) column "Number," sequential number of events of the type B,

(2) column "Second," occurrence time (JST) in second of the event,

(3) column "Hour," occurrence time (JST) in hour,

(4) column "Type," sub-group type of the B event,

(5) column "Strength," peak height of the pulse, in milivolt,

(6) column "Duration," width of pulse, in milisecond,

(7) column "Comment," several features of waveforms: appearance of $\mathrm{P}$ phase, association of subevent, complex type, and so forth.

\section{Acknowledgments}

This work was supported by JST Grant AS2121347A to OKI Engineering Co., Ltd. The authors thank T. Matsumoto and Y. Okada (NIED) for support to use the borehole and F. Freund and W. C Lai, K. Hattori, and Q. H. Huang for valuable discussions and comments. Detailed and valuable comments by Editor Professor J. P. Makris and reviewer K. Eftaxias are greatly appreciated. The authors used data of K-NET at CHB005.

\section{References}

[1] K. Mogi, Earthquake Prediction, Academic Press, Tokyo, Japan, 1985.

[2] T. Rikitake, Earthquake Forecasting and Warning, Tokyo Center for Academic Publications, D. Reidel Publishing, Tokyo, Japan, 1982.
[3] C. H. Scholz, The Mechanics of Earthquake and Faulting, Cambridge University Press, Cambridge, Mass, USA, 2nd edition, 2002.

[4] L. M. Jones and P. Molnar, "Some characteristics of foreshocks and their possible relationship to earthquake prediction and premonitory slip on faults," Journal of Geophysical Research, vol. 84, no. 7, pp. 3596-3608, 1979.

[5] M. Ohnaka, "A shear failure strength law of rock in the brittleplastic transition regime," Geophysical Research Letters, vol. 22, no. 1, pp. 25-28, 1995.

[6] K. Maeda, "Time distribution of immediate foreshocks obtained by a stacking method," Pure and Applied Geophysics, vol. 155, no. 2-4, pp. 381-394, 1999.

[7] D. Sornette and C. Sammis:, "Complex critical exponents from renormalization group theory of Earthquakes: implications for Earthquake predictions," Journal de Physique I, vol. 5, no. 5, pp. 607-619, 1995.

[8] P. Kapiris, K. Nomicos, G. Antonopoulos et al., "Distinguished seismological and electromagnetic features of the impending global failure: did the 7/9/1999 M5.9 Athens earthquake come with a warning?" Earth, Planets and Space, vol. 57, no. 3, pp. 215230, 2005.

[9] K. Eftaxias, S. M. Potirakisb, and T. Chelidzec, "On the puzzlingfeature of the silence of precursory electromagnetic emissions," http://arxiv.org/abs/1211.5151.

[10] X. Lei, K. Kusunose, M. V. M. S. Rao, O. Nishizawa, and T. Satoh, "Quasi-static fault growth and cracking in homogeneous brittle rock under triaxial compression using acoustic emission monitoring," Journal of Geophysical Research B, vol. 105, no. 3, pp. 6127-6139, 2000.

[11] S. Yoshida, P. Manjgaladze, D. Zilpimiani, M. Ohnaka, and M. Nakatani, "Electromagnetic emissions associated with frictional sliding of rock," in Electromagnetic Phenomena Related to Earthquake Prediction, M. Hayakawa and Y. Fujinawa, Eds., pp. 307-322, Terrapub, Tokyo, Japan, 1994.

[12] S. Yoshida, O. C. Clint, and P. R. Sammonds, "Electric potential changes prior to shear fracture in dry and saturated rocks," Geophysical Research Letters, vol. 25, no. 10, pp. 1577-1580, 1998.

[13] S. Yoshida and T. Ogawa, "Electromagnetic emissions from dry and wet granite associated with acoustic emissions," Journal of Geophysical Research B, vol. 109, no. 9, Article ID B09204, 2004.

[14] X. Lei, K. Masuda, O. Nishizawa et al., "Detailed analysis of acoustic emission activity during catastrophic fracture of faults in rock," Journal of Structural Geology, vol. 26, no. 2, pp. 247258, 2004.

[15] M. Hayakawa and Y. Fujinawa, Eds., Electromagnetic Phenomena Related to Earthquake Prediction, Terra Scientific Publishing Company, Tokyo, Japan, 1994.

[16] M. Hayakawa, Ed., Atmospheric and Ionospheric Electromagnetic Phenomena Associated with Earthquake, Terra Scientific Publishing Company, Tokyo, Japan, 1999.

[17] K. Eftaxias and S. M. Potirakis, "Current challenges for preseismic electromagnetic emissions: shedding light from microscale plastic flow, granular packings, phase transitions and selfaffinity notion of fracture process," http://arxiv.org/ftp/arxiv/ papers/1301/1301.1045.pdf.

[18] V. P. Drnevich and R. E. Gray, Acoustic Emissions in Geotechnical Engineering Practice, American Society for Testing and Materials (ASTM), Philadelphia, Pa, USA, 1981.

[19] V. A. Morgunov, M. N. Lubashevsky, V. Z. Fubrizius, and Z. E. Fubrizius, "Geoacoustic precursor of Spitak earthquake," Volcanology and Seismology, vol. 4, pp. 104-107, 1991. 
[20] K. Hattori, "Results of acoustic emission observation at Matsushiro station, Japan," Final Report, International Frontier Research Group on Earthquakes (RIKEN IFREQ), Group Director Seiya Uyeda, 2003.

[21] O. Molchanov, A. Schekotov, M. Solovieva et al., "Near-seismic effects in ULF fields and seismo-acoustic emission: statistics and explanation," Natural Hazards and Earth System Science, vol. 5, no. 1, pp. 1-10, 2005.

[22] S. K. Park, M. J. S. Johnston, T. R. Madden, F. D. Morgan, and H. F. Morrison, "Electromagnetic precursors to earthquakes in the ulf band: a review of observations and mechanisms," Reviews of Geophysics, vol. 31, no. 2, pp. 117-132, 1993.

[23] Y. Fujinawa, T. Kumagai, and K. Takahashi, "A study of anomalous underground electric field variations associated with a volcanic eruption," Geophysical Research Letters, vol. 19, no. 1, pp. 9-12, 1992.

[24] Y. Fujinawa and K. Takahashi, "Electromagnetic radiations associated with major earthquakes," Physics of the Earth and Planetary Interiors, vol. 105, no. 3-4, pp. 249-259, 1998.

[25] Y. Fujinawa, K. Takahashi, T. Matsumoto et al., "Electric field variations related with seismic swarms," Bulletin of the Earthquake Research Institute, vol. 76, pp. 391-415, 2001.

[26] Y. Fujinawa, T. Matsumoto, and K. Takahashi, "Modeling confined pressure changes inducing anomalous electromagnetic fields related with earthquakes," Journal of Applied Geophysics, vol. 49, no. 1-2, pp. 101-110, 2002.

[27] Y. Fujinawa and K. Takahashi, "Emission of electromagnetic radiation preceding the Ito seismic swarm of 1989," Nature, vol. 347, no. 6291, pp. 376-378, 1990.

[28] K. Takahashi, Y. Fujinawa, T. Matsumoto et al., "An anomalous electric field variation with the seismic swarm(1)- underground electric field observation at Hodaka station (1995-1999)," Technical Notes 204, National Research Institute for Earth Science and Disaster Prevention, 2000, http://dil-opac.bosai.go.jp/publication/nied_tech_note/pdf/KJ-01_204.pdf.

[29] B. Nourbehect, Irreversible thermodynamic effects in inhomogeneous media and their applications in certain geoelectric problems [Ph.D. thesis], Massachusetts Institute of Technology, Cambridge, Mass, USA, 1963.

[30] V. Fitterman, "Electrokinetic and magnetic anomalies associated with dilatant regions in a layered Earth," Journal of Geophysical Research, vol. 83, pp. 5923-5928, 1978.

[31] T. Ishido and J. Muzutani, "Experimental and theoretical basis of electrokinetic phenomena in rock-water systems and its applications to geophysics," Journal of Geophysical Research, vol. 86, no. 3, pp. 1763-1775, 1981.

[32] Y. Fujinawa, K. Takahashi, Y. Noda, H. Iitaka, and S. Yazaki, "Remote detection of the electric field change induced at the seismic wave front the start of fault rupturing," International Journal of Geophysics, vol. 2011, Article ID 752193, 11 pages, 2011.

[33] W. Suzuki, S. Aoi, H. Sekiguchi, and T. Kunugi, "Rupture process of the 2011 Tohoku-Oki mega-thrust earthquake (M9.0) inverted from strong-motion data," Geophysical Research Letters, vol. 38, no. 7, pp. 1944-8007, 2011.

[34] W.-C. Lai, K.-C. Hsu, C.-L. Shiehu et al., "Evaluation of the effects of ground shaking and static volumetric strain change on earthquake-related groundwater level changes in Taiwan," Earth, Planets and Space, vol. 62, no. 4, pp. 391-400, 2010.

[35] T. Nagao, Y. Orihara, T. Yamaguchi et al., "Co-seismic geoelectric potential changes observed in Japan," Geophysical Research Letters, vol. 27, no. 10, pp. 1535-1538, 2000.
[36] A. Revil and G. Saracco, "The volcano-electric effect," Journal of Geophysical Research, vol. 108, pp. 2251-2270, 2003.

[37] P. Han, Investigation of ULF seismo-magnetic phenomena in Kanto, Japan during 2000-2010 [Ph.D. thesis], Chiba University, 2012.

[38] J. R. Moore and S. D. Glaser, "Self-potential observations during hydraulic fracturing," Journal of Geophysical Research, vol. 112, Article ID B02204, 2007.

[39] M. A. Fenoglio, M. J. S. Johnston, and J. D. Byerlee, "Magnetic and electric fields associated with changes in high pore pressure in fault zones: application to the Loma Prieta ULF emissions," Journal of Geophysical Research, vol. 100, no. 7, pp. 12951-12958, 1995.

[40] A. C. Fraser-Smith, A. Bernardi, P. R. McGill, M. E. Ladd, R. A. Helliwell, and O. G. Villard Jr., "Low-frequency magnetic field measurements near the epicenter of the Ms 7.1 Loma Prieta earthquake," Geophysical Research Letters, vol. 17, no. 9, pp. 1465-1468, 1990.

[41] E. J. Sellers, M. O. Kataka, and L. M. Linzer, "Source parameters of acoustic emission events and scaling with mining-induced seismicity," Journal of Geophysical Research B, vol. 108, no. 9, pp. $1-16,2003$.

[42] N. E. Timms, D. Healy, J. M. Reyes-Montes, D. S. Collins, D. J. Prior, and R. P. Young, "Effects of crystallographic anisotropy on fracture development and acoustic emission in quartz," Journal of Geophysical Research, vol. 115, Article ID B07202, 2010.

[43] X. Lei, K. Kusunose, M. V. M. S. Rao, O. Nishizawa, and T. Satoh, "Quasi-static fault growth and cracking in homogeneous brittle rock under triaxial compression using acoustic emission monitoring," Journal of Geophysical Research B, vol. 105, no. 3, pp. 6127-6139, 2000.

[44] D. J. Varnes, "Predicting earthquakes by analyzing accelerating precursory seismic activity," Pure and Applied Geophysics, vol. 130, no. 4, pp. 661-686, 1989.

[45] N. Yoshioka and C. H. Scholz, "Elastic properties of contacting surfaces under normal and shear loads: 2. Comparison of theory with experiment," Journal of Geophysical Research B, vol. 94, no. 12, pp. 17691-17700, 1989.

[46] Y. Fujinawa, K. Takahashi, T. Matsumoto, and N. Kawakami, "Experiments to locate sources of earthquake-related VLF electromagnetic signals," Proceedings of the Japan Academy B, vol. 73, no. 3, pp. 33-38, 1997.

[47] M. Parrot, D. Benoist, J. J. Berthelier et al., “The magnetic field experiment IMSC and its data processing onboard DEMETER: scientific objectives, description and first results," Planetary and Space Science, vol. 54, no. 5, pp. 441-455, 2006.

[48] O. Hasegawa, Y. Hosokawa, T. Mori, A. Takeichi, and H. Fujii, "Application of AE monitoring for rock burst and rock noise phenomenon under tunnel construction," Japan Civil Engineering Society, 2008.

[49] N. Gershenzon and G. Bambakidis, "Modeling of seismoelectromagnetic phenomena," Russian Journal of Earth Sciences, vol. 3, no. 4, pp. 247-275, 2001.

[50] S. Pride, "Governing equations for the coupled electromagnetics and acoustics of porous media," Physical Review B, vol. 50, no. 21, pp. 15678-15696, 1994.

[51] M. W. Haartsen and S. R. Pride, "Electroseismic waves from point sources in layered media," Journal of Geophysical Research $B$, vol. 102, no. 11, pp. 24745-24769, 1997.

[52] A. H. Araji, A. Revil, A. Jardani, B. J. Minsley, and M. Karaoulis, "Imaging with cross-hole seismoelectric tomography," Geophysical Journal International, vol. 188, no. 3, pp. 1285-1302, 2012. 
[53] F. C. Schoemaker, N. Grobbe, M. D. Schakel, S. A. L. de Ridder, E. C. Slob, and D. M. J. Smeulders, "Experimental validation of the electrokinetic theory and development of seismoelectric interferometry by cross-correlation," International Journal of Geophysics, vol. 2012, Article ID 514242, 23 pages, 2012.

[54] Y. Gao and H. Hu, "Seismoelectromagnetic waves radiated by a double couple source in a saturated porous medium," Geophysical Journal International, vol. 181, no. 2, pp. 873-896, 2010.

[55] Y. Huang, H. Saleur, and D. Sornette, "Reexamination of log periodicity observed in the seismic precursors of the 1989 Loma Prieta earthquake," Journal of Geophysical Research B, vol. 105, no. 12, pp. 28111-28123, 2000.

[56] H. X. Ren, X. F. Chen, and Q. H. Huang, "Numerical simulation of coseismic electromagnetic fields associated with seismic waves due to finite faulting in porous media," Geophysical Journal International, vol. 188, no. 3, pp. 925-944, 2012.

[57] Y. Honkura, M. Matsushima, Ş. Barış et al., "Rapid changes in the electrical state of the 1999 Izmit earthquake rupture zone," Nature Communications, vol. 4, article 2116, 2013. 

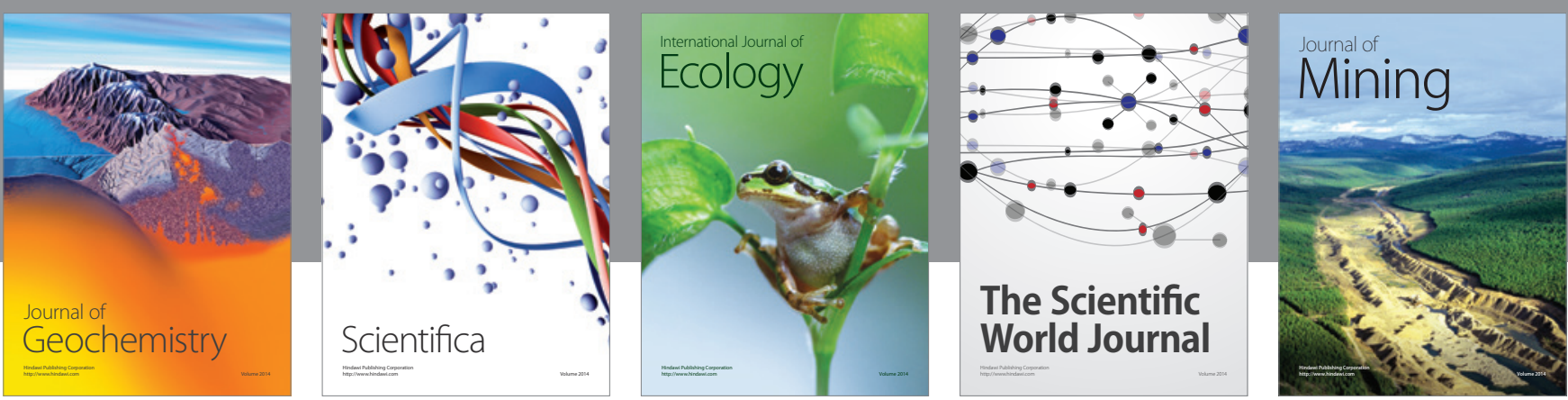

The Scientific World Journal
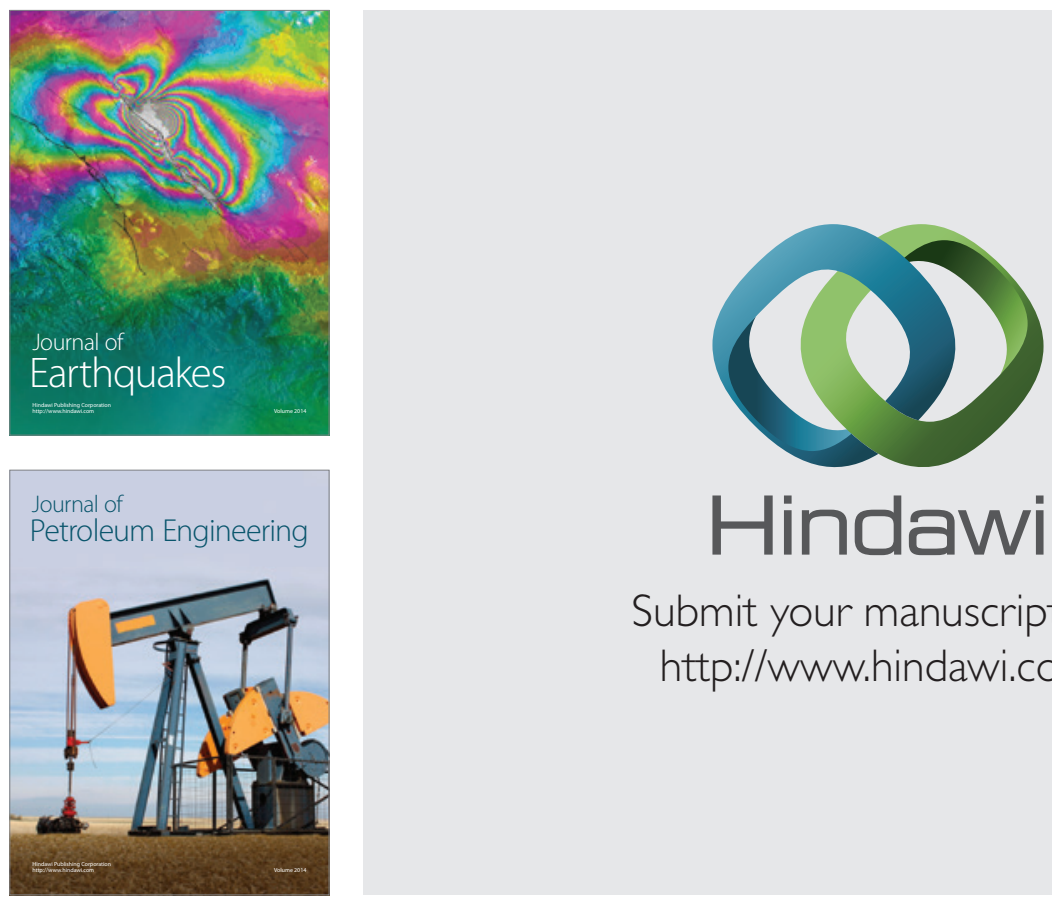

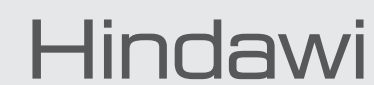

Submit your manuscripts at

http://www.hindawi.com
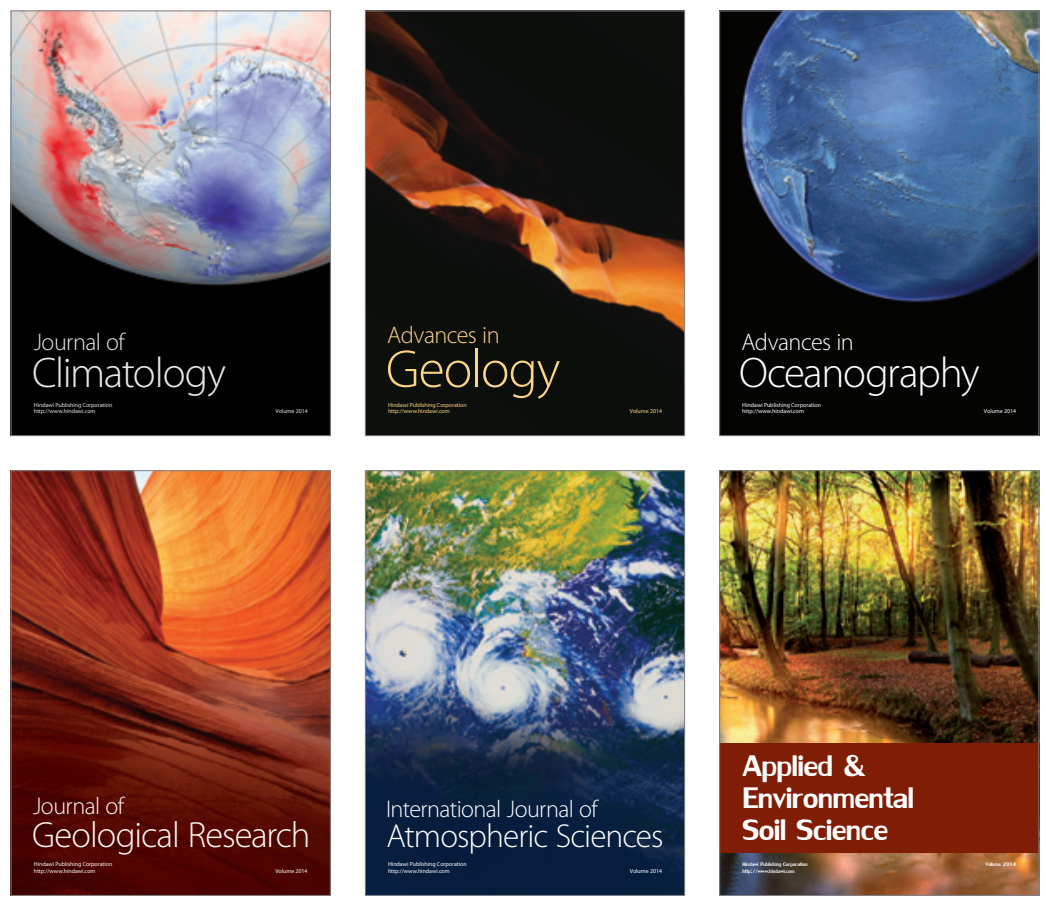
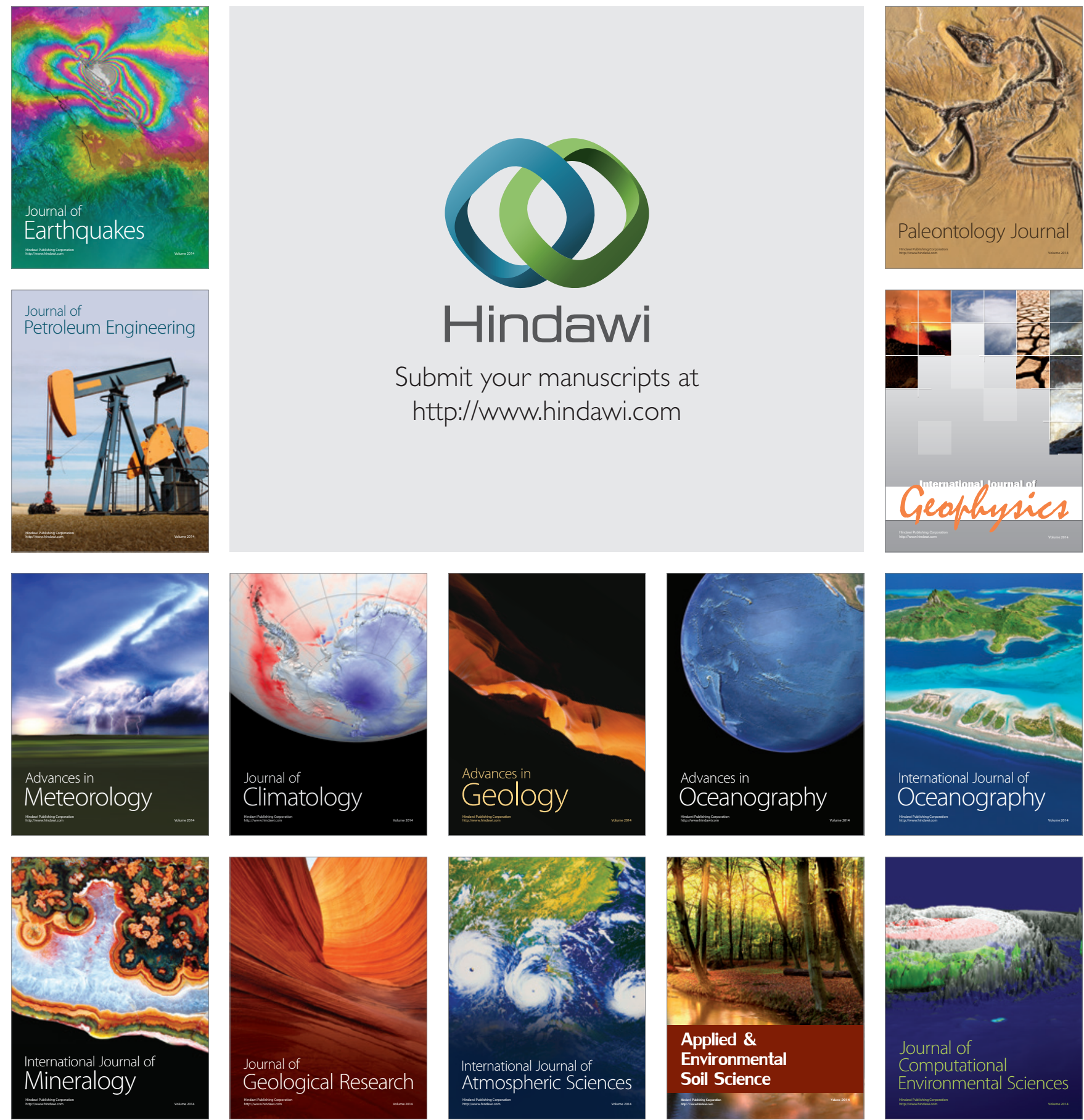